ARTICLE

Received 8 Jan 2014 | Accepted 22 May 2014 | Published 28 Aug 2014

DOI: $10.1038 /$ ncomms5202

\title{
Structure and mechanism of action of the hydroxy-aryl-aldehyde class of IRE1 endoribonuclease inhibitors
}

Mario Sanches ${ }^{1, \star}$, Nicole M. Duffy ${ }^{1, \star}$, Manisha Talukdar ${ }^{1,2, \star}$, Nero Thevakumaran ${ }^{1,3}$, David Chiovitti ${ }^{1}$, Marella D. Canny ${ }^{1}$, Kenneth Lee ${ }^{1,2}$, Igor Kurinov ${ }^{4}$, David Uehling ${ }^{5}$, Rima Al-awar ${ }^{5,6}$, Gennadiy Poda ${ }^{5}$, Michael Prakesch ${ }^{5}$, Brian Wilson ${ }^{5}$, Victor Tam7, Colleen Schweitzer ${ }^{7}$, Andras Toro ${ }^{7}$, Julie L. Lucas ${ }^{7}$, Danka Vuga ${ }^{7}$, Lynn Lehmann ${ }^{8}$, Daniel Durocher ${ }^{1,2}$, Qingping Zeng ${ }^{7}$, John B. Patterson ${ }^{7}$ \& Frank Sicheri ${ }^{1,2,3}$

Endoplasmic reticulum (ER) stress activates the unfolded protein response and its dysfunction is linked to multiple diseases. The stress transducer IRE1 $\alpha$ is a transmembrane kinase endoribonuclease (RNase) that cleaves mRNA substrates to re-establish ER homeostasis. Aromatic ring systems containing hydroxy-aldehyde moieties, termed hydroxy-aryl-aldehydes (HAA), selectively inhibit IRE1 $\alpha$ RNase and thus represent a novel chemical series for therapeutic development. We solved crystal structures of murine IRE1 $\alpha$ in complex with three HAA inhibitors. HAA inhibitors engage a shallow pocket at the RNase-active site through pi-stacking interactions with His910 and Phe889, an essential Schiff base with Lys907 and a hydrogen bond with Tyr892. Structure-activity studies and mutational analysis of contact residues define the optimal chemical space of inhibitors and validate the inhibitor-binding site. These studies lay the foundation for understanding both the biochemical and cellular functions of IRE1 $\alpha$ using small molecule inhibitors and suggest new avenues for inhibitor design.

\footnotetext{
${ }^{1}$ Centre for Systems Biology, Lunenfeld-Tanenbaum Research Institute, Mount Sinai Hospital, Toronto, Ontario, Canada M5G 1X5. ${ }^{2}$ Department of Molecular Genetics, University of Toronto, Toronto, Ontario, Canada M5S 1A8. ${ }^{3}$ Department of Biochemistry, University of Toronto, Toronto, Ontario, Canada M5S 1A8. ${ }^{4}$ NE-CAT APS, Building 436E, Argonne National Lab, 9700 S.Cass Avenue, Argonne, Illinois 60439, USA. ${ }^{5}$ Drug Discovery Program, Ontario Institute for Cancer Research, Toronto, Ontario, Canada M5G 0A3. ${ }^{6}$ Department of Pharmacology and Toxicology, University of Toronto, Toronto, Ontario, Canada M5S 1A8. ${ }^{7}$ MannKind Corporation, 28903 North Avenue Paine, Valencia, California 91355, USA. ${ }^{8}$ NanoTemper Technologies, Inc., 395 Oyster Point Boulevard, Suite 135, South San Francisco, California 94080, USA. * These authors contributed equally to this work. Correspondence and requests for materials should be addressed to J.B.P. (email: jpatterson@mankindcorp.com) or to F.S. (email: sicheri@lunenfeld.ca).
} 
E ndoplasmic reticulum (ER) stress and the resulting unfolded protein response (UPR) have gained significant interest as an area in which targeted molecules may have extensive therapeutic overlap in divergent disease types including neurodegeneration, inflammation, metabolic syndromes and cancer ${ }^{1,2}$. The ER is a large intracellular compartment responsible for the production of secreted and cell surface proteins as well as cellular lipid biosynthesis and membrane generation. The ER is physically connected to both the nucleus and the mitochondria and is fundamentally integrated with global cellular regulatory networks and metabolism. Protein folding, membrane and nutrient perturbations within the ER, arising from exogenous or internal stresses, induce the $\mathrm{UPR}^{3}$. This cellular signalling response serves to alleviate the imposing stress and corrects the imbalance to restore normal cellular homeostasis. However, accumulating evidence suggests that the UPR, when chronically activated due to a myriad of stimuli, may be pathological resulting in inflammation, cell death or conversely may be exploited by cancer cells to ensure survival ${ }^{1,3-5}$.

The three major arms of the fully integrated UPR include PERK (pancreatic eIF2alpha kinase), ATF6 (activating transcription factor 6) and IRE1 (inositol-requiring enzyme 1), which function as a finely tuned triad. All three arms have overlapping yet distinct responsibilities and regulate a plethora of downstream genes $^{3}$. PERK, an ER-resident transmembrane eIF- $2 \alpha$ kinase, halts translation ${ }^{6}$ to induce transcriptional programs via nonconventional translation of ATF4, which results in both pro-life and pro-death outcomes ${ }^{7}$. During ER stress, ATF6 is translocated to the Golgi where it undergoes proteolysis at the membrane releasing it to the nucleus ${ }^{8}$ where it transactivates genes required for the UPR ${ }^{9}$.

IRE1, the most conserved arm of the UPR, is a unique ER transmembrane fused dual kinase-endoribonuclease ${ }^{10}$ that directly regulates $\mathrm{HAC} 1$ in yeast or its metazoan orthologue XBP1 (refs 3,4). Fungi possess a single isoform of IRE1, while higher eukaryotes generally possess two isoforms denoted IRE $1 \alpha$ and $\beta$. The endoribonuclease (RNase) domain of IRE1, which appears unique to eukaryotes ${ }^{11-15}$, is found in only one other paralogue, RNase $\mathrm{L}^{16}$, an enzyme involved in innate immunity in vertebrates ${ }^{17}$. UPR signalling initiates from the IRE1 luminal domain, which senses the accumulation of unfolded protein, proceeds by dimerization and oligomerization to activate the cytoplasmic auto-kinase activity 18,19 and in turn RNase activity ${ }^{10,20}$. In metazoan organisms, selective cleavage of dual stem loops within the XBP1 mRNA ensues and a 26-nucleotide intron is removed ${ }^{21-23}$. The two exon ends are then ligated by an unknown process ${ }^{24}$ allowing the spliced XBP1 (XBP1s) transcript to be translated into a functional transcription factor. XBP1s directs the transcription of chaperones, ERAD (ER-associated protein degradation) components and other targets involved in ER expansion, phospholipid synthesis and general homeostasis ${ }^{25}$. Combined, the downstream activities of the XBP1s transcriptional network can enforce specialized cellular functions such as antibody secretion in plasma cells ${ }^{26}$. In addition to XBP1 mRNA, IRE1 also cleaves a selected set of ER-targeted mRNAs ${ }^{27}$. This process, termed RIDD (regulated IRE1-dependent decay) ${ }^{28}$, attempts to rapidly decrease the secretory load during ER stress; however, little is known about its physiological significance ${ }^{28,29}$. Recent evidence suggests that IRE1 $\alpha$ can be activated in response to specific signalling events independent of the UPR, which have cell type- or organ-specific functions and can be dependent ${ }^{30}$ or independent of XBP1 (refs 31,32). The kinetics of IRE1 $\alpha$ signalling usually follows a rapid on-off response where activation is followed by rapid deactivation ${ }^{33}$, which can have longer-term consequence ${ }^{34}$. This is achieved by yeast IRE1 through dephosphorylation ${ }^{35}$ or hyperphosphorylation ${ }^{36}$ of the kinase.
Small molecule modulators of IRE1 kinase and RNase functions have been reported with distinct mechanisms of action reflecting the engagement of three physically distinct binding sites. Kinase domain active site binders inhibit kinase output by virtue of ATP competition and paradoxically can either potentiate $^{37,38}$ or inhibit ${ }^{39}$ RNase output depending on the underlying chemotype. The structural basis for their differential effect on RNase function has not been resolved since X-ray crystal structures of RNase inhibitors bound to the IRE1 kinase domain specifically are lacking. Quercetin, representative of a second class of modulators, marginally influences the kinase output of yeast IRE1 while potently enhancing RNase output by promoting molecular dimerization through engagement of a composite binding pocket at the enzyme-dimer interface ${ }^{40}$. Salicylaldehyde derivatives represent a third class of modulators that potently, reversibly and selectively inhibit IRE1 RNase activity ${ }^{41}$, with weak effects on protein kinase function. Additional compounds using the adjacent hydroxy-aldehyde motif and dual-ring biphenyl (WO 2008/154484 A1), naphthalene (WO 2008/154484 A1; WO 2011/056744 A1) and coumarin (WO 2011/127070 A2) aromatic systems, which we collectively refer to as hydroxy-aryl-aldehydes (HAA), were also found to be potent IRE1 RNase inhibitors ${ }^{42-44}$ Notably, a combination of methods including chemical modification of the protein/HAA inhibitor complex demonstrated that the aldehyde forms a reversible Schiff base with lysine 907 in the active site region of the RNase domain ${ }^{43}$. These findings were surprising and offered hope for the selective and potent targeting of IRE1 where RNase-active sites in general have made poor drug targets as they possess hydrophobic pockets that are shallow or non-existent due to a requirement for extensive interactions with the RNA phosphodiester backbone.

Here we uncover the structural basis for HAA inhibitor mechanism of action through a detailed X-ray crystallographic study of three members, representative of two different chemical scaffolds, in complex with murine IRE1 $\alpha$ (referred here generally as IRE1 $\alpha$ ). These structures and follow-up analyses allow for a rationalization of structure-activity relationships (SARs) and suggest avenues for future optimization.

\section{Results}

Co-crystallization and characterization of HAA inhibitors. To discern the mechanism of action of the HAA class of IRE1specific endoribonuclease inhibitors, we pursued X-ray crystallographic analyses of HAA members in complex with the dual catalytic region of IRE1. In an extensive screening campaign, sampling combinations of HAA inhibitors with nucleotides, protein kinase inhibitors and IRE1 $\alpha$ orthologues (yeast, zebrafish, human and mouse) with different $\mathrm{N}$-terminal domain boundaries and phosphorylation states, we obtained suitable co-crystals for three HAA inhibitors, namely, MKC9989, OICR464 and OICR573 (see Fig. 1a for chemical structures and substituent numbering schemes). Each was obtained in complex with $\mathrm{Mg}^{2+}$ / ADP and an auto-phosphorylated minimal dual catalytic domain fragment of murine IRE1 $\alpha$ encompassing residues 549-977. The crystals diffracted at $2.9,3.0$ and $3.4 \AA$ resolution, respectively, and the co-structures were solved by molecular replacement using the human IRE1 $\alpha$ crystal structure as a search model (see Methods for experimental details and Table 1 for data collection and refinement statistics).

MKC9989, OICR464 and OICR573 inhibitors visualized in IRE1 $\alpha$ co-structures potently inhibited the RNase activity of murine and human IRE1 $\alpha$, and to a lesser degree yeast IRE1 in the case of MKC9989 in vitro with $\mathrm{IC}_{50}$ s ranging from 0.23 to $44 \mu \mathrm{M}$ (Fig. 1b). In contrast, the same inhibitors had no effect or weakly inhibited the auto-kinase activity of IRE1 $\alpha$ at the highest 
a
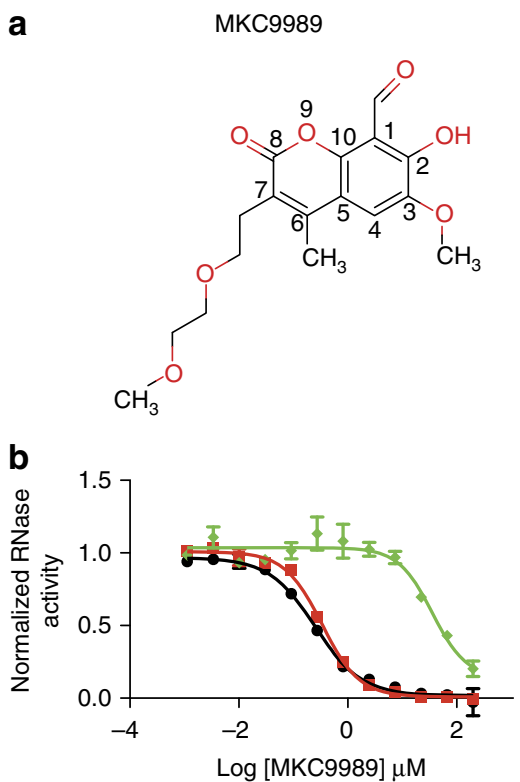

$\mathrm{IC}_{50}$

$\rightarrow$ Human IRE $1 \alpha \quad 0.23 \pm 0.03 \mu \mathrm{M}$

$\rightarrow$ - Mouse IRE1 $\alpha \quad 0.29 \pm 0.04 \mu \mathrm{M}$

$\rightarrow$ Yeast IRE1 $44 \pm 10 \mu \mathrm{M}$

c
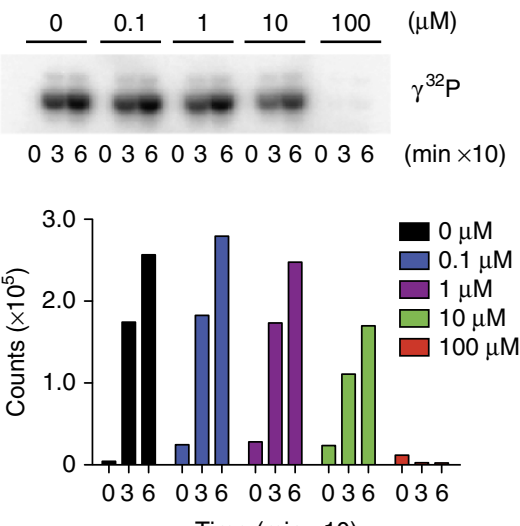

OICR464<smiles>COc1cc(-c2ccc3c(c2)OCCN3C)cc(C=O)c1O</smiles>

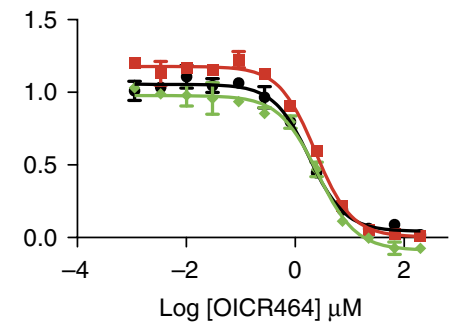

$\mathrm{IC}_{50}$

$\rightarrow-$ Human IRE1 $\alpha \quad 2.3 \pm 0.69 \mu \mathrm{M}$

$\rightarrow$ Mouse IRE1 $\alpha \quad 5.4 \pm 5.2 \mu \mathrm{M}$

$\leadsto$ Yeast IRE1 $2.2 \pm 0.39 \mu \mathrm{M}$
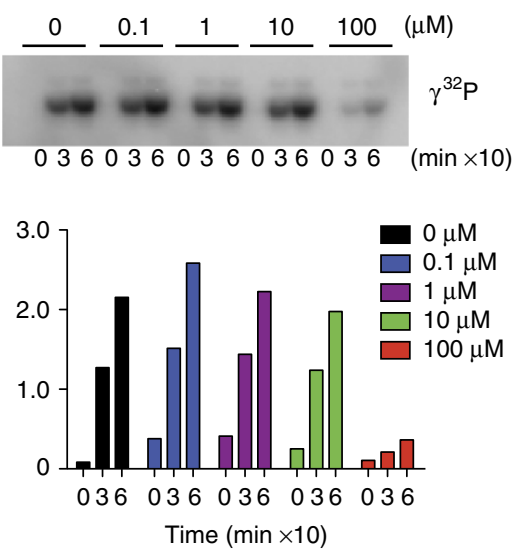

OICR573<smiles>COc1cc(-c2ccc(N3CCOCC3)cc2)cc(C=O)c1O</smiles>

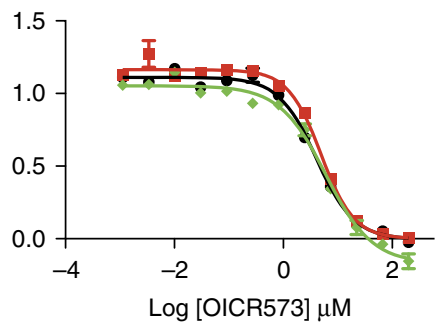

$\mathrm{IC}_{50}$

$\rightarrow$ Human IRE1 $\alpha \quad 5.4 \pm 1.9 \mu \mathrm{M}$

$\rightarrow-$ Mouse IRE1 $\alpha \quad 11 \pm 9.9 \mu \mathrm{M}$

$\multimap$ Yeast IRE1 $6.5 \pm 0.66 \mu \mathrm{M}$
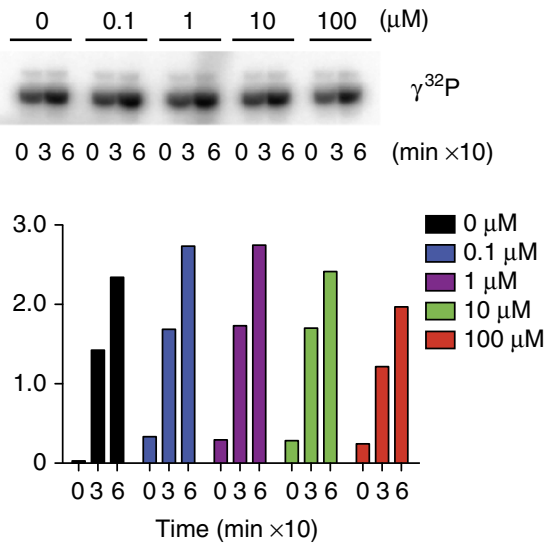

Figure 1 | Functional characterization of HAA inhibitors solved in complex with IRE1 . (a) Chemical structure and substituent numbering scheme of HAA inhibitors. (b) Inhibition of IRE1 RNase activity by HAA inhibitors using a real-time fluorescence readout assay. IC $C_{50} S$ derived from fitted profiles represent the mean \pm s.d., $n=6$ (three experiments performed in duplicate) for murine IRE1 $\alpha$ and yeast IRE1 and $n=4$ (two experiments performed in duplicate) for human IRE1 $\alpha$. Shown are representative profiles for one experiment performed in duplicate. (c) Inhibition of IRE1 $\alpha$ auto-kinase activity by HAA inhibitors.

concentrations tested $\left(\mathrm{IC}_{50} \mathrm{~s} \gg 10 \mu \mathrm{M}\right)$ (Fig. 1c). In the case of OICR464 and OICR573 (and to a lesser extent MKC9989), inhibitor potency showed a significant dependency on preincubation time with IRE1 $\alpha$ (Supplementary Fig. 1). This may reflect differences in the reactivity of the aldehyde group in each HAA scaffold required to support formation of a Schiff base interaction with Lys907. At $10 \mu \mathrm{M}$ concentration, MKC9989 completely inhibited both basal and thapsigargin-induced splicing of XBP1 mRNA (Fig. 2a). These effects were observed even in cells pre-treated with thapsigargin, indicating that MKC9989 can fully reverse the onset of XPB1 splicing after the UPR is initiated. In parallel analyses, MKC9989 markedly stabilized the RIDD target CD59 mRNA $^{45}$ when co-administered with thapsigargin relative to thapsigargin treatment alone and modestly increased levels of CD59 mRNA in non-stressed cells, the latter likely reflecting the inhibition of baseline RIDD activity. In contrast to the effects on XBP1 splicing, MKC9989 moderately stabilized
CD59 levels when administered $2 \mathrm{~h}$ post treatment with thapsigargin. Finally, the potency of MKC9989 against the splicing of $X B P 1$ mRNA $\left(\mathrm{EC}_{50}=0.33 \mu \mathrm{M}\right)$ was comparable to its potency against RNA cleavage in vitro (Fig. 1b). These functional properties in total suggested that the MKC9989, OICR464 and OICR573 X-ray co-structures could help illuminate the mechanism of action of the HAA class of inhibitors in vitro and in cells.

Structure overview. In all three HAA co-structures, IRE1 $\alpha$ crystallized in the same face-to-face dimer configuration adopted by human IRE $1 \alpha^{46}$, and not the back-to-back dimer or oligomer configuration adopted by yeast IRE1 (refs 11,37) (Fig. 3a). This conservation lends further support to the notion that the face-to-face dimer configuration is a functionally relevant conformation for IRE1 $\alpha$ and raises the question why the human and mouse IRE1 orthologues did not adopt the back-to- 
Table 1 | Data collection and refinement statistics.

IRE1 $\alpha$ MKC9989

\begin{tabular}{|c|c|}
\hline \multicolumn{2}{|l|}{ Data collection } \\
\hline Space group & C 121 \\
\hline \multicolumn{2}{|l|}{ Cell dimensions } \\
\hline$a, b, c(\AA)$ & $246.08,90.5,72.13$ \\
\hline$\alpha, \beta, \gamma\left(^{\circ}\right)$ & $90.00,91.88,90.00$ \\
\hline Resolution $(\AA)$ & $72.09-2.90(2.98-2.90)$ \\
\hline$R_{\text {meas }}(\%)$ & $15.3(99.8)$ \\
\hline$R_{\text {merge }}(\%)$ & $35.6(172.7)$ \\
\hline$|/ \sigma|$ & $7.14(1.17)$ \\
\hline Completeness (\%) & $96.2(99.7)$ \\
\hline Redundancy & $3.69(3.34)$ \\
\hline \multicolumn{2}{|l|}{ Refinement } \\
\hline Resolution $(\AA)$ & $72.09-2.90$ \\
\hline No. of reflections & 21,855 \\
\hline$R_{\text {work }} / R_{\text {free }}$ & $0.2015 / 0.2324$ \\
\hline \multicolumn{2}{|l|}{ No. of atoms } \\
\hline Protein & 6,220 \\
\hline Ligand/ion & 102 \\
\hline Water & 0 \\
\hline \multicolumn{2}{|l|}{$B$ factors } \\
\hline Protein & 60.0 \\
\hline Inhibitor & 64.6 \\
\hline Other ligands & 48.5 \\
\hline \multicolumn{2}{|l|}{ r.m.s. deviations } \\
\hline Bond lengths $(\AA)$ & 0.018 \\
\hline Bond angles $\left({ }^{\circ}\right)$ & 1.37 \\
\hline
\end{tabular}

IRE1 $\alpha$ OICR573

C 121

$319.24,63.03,140.78$

$90.00,99.49,90.00$

48.27-3.40 (3.60-3.40)

$17.2(93.9)$

$30.9(121.9)$

$8.69(1.74)$

$94.5(97.3)$

$3.71(3.71)$

48.27-3.40

29,201

$0.2219 / 0.2852$

12,448

165

0

87.9

115.9

71.5

0.006

1.18
IRE1 $\alpha$ OICR464

C 121

$319.11,62.31,141.33$

$90.00,99.57,90.00$

46.60-3.00 (3.18-3.00)

$7.8(91.2)$

$22.3(158.0)$

$11.08(1.33)$

$96.2(96.6)$

$2.25(2.24)$

46.60-3.00

40,131

$0.2100 / 0.2759$

12,316

152

0

90.0

107.7

69.3

0.012

1.32

Data were collected from a single crystal in each case. Highest-resolution shell is shown in parenthesis.

back dimer configuration reflective of the 'RNase-active' state. Each protomer of IRE1 $\alpha$ consisted of a bilobal protein kinase domain rigidly fused through the kinase C-lobe to an $\alpha$-helical RNase domain. All IRE1 $\alpha$ protomers in each co-structure displayed unambiguous density for $\mathrm{Mg}^{2}+/ \mathrm{ADP}$ in the catalytic cleft of the kinase domain (Supplementary Fig. 2a). Minimally, one IRE1 $\alpha$ protomer per co-structure displayed a well-ordered HAA inhibitor engaging the active site of the RNase domain (Supplementary Fig. 2a,b). The remaining RNase-active sites were occluded by crystal packing, or weak electron density precluded accurate modelling of the bound inhibitor. IRE1 $\alpha$ protomers were well ordered with the exception of $\sim 13$ residues at both $\mathrm{N}$ and $\mathrm{C}$ termini and also within the kinase domain activation segment (residues 719-730). IRE1 $\alpha$ protomers were highly similar to each other (r.m.s.d. $=0.24 \AA^{2}$ over 10 total molecules in the asymmetric unit of the three HAA co-structures), to human IRE1 $\alpha$ protomers (Protein Data Bank (PDB) 3P23, r.m.s.d. $=1.28 \AA^{2}$ ) and to yeast IRE1 protomers (PDB 3LJ0, r.m.s.d. $=1.48 \AA^{2}$ ).

Binding mode of HAA inhibitors to the RNase domain of IRE1. The structure of the IRE1 $\alpha$ RNase domain consisted of nine $\alpha$-helices (denoted helices $\alpha 1-\alpha 8$ and $\alpha 3^{\prime}$ ). All three HAA inhibitors shared similar binding modes with a shallow pocket nestled at the nexus of helices $\alpha 3^{\prime}, \alpha 4$ and $\alpha 5$, and lined by the side chains of Glu913, Leu914, Pro915, Phe889, Leu886, Lys907 and Arg902, and the invariant or highly conserved catalytic residues Tyr892, Arg905, Asn906, His910 and Arg902 (Fig. 3b, Supplementary Fig. 3a,b). Using the human IRE1 $\alpha$ structure (PDB3P23) as a reference for the apo state of the RNase domain, comparison with IRE1 $\alpha$ in complex with HAA inhibitors revealed that the HAA-binding pocket was largely preformed (Supplementary Fig. 3c,d). Small induced conformational changes consisted of: (1) enforcement of a single rotomer conformer for
Asn906 and His910 that enlarged the binding pocket to accommodate the HAA ring structure and (2) a clamping movement of the Phe889 side chain (5.1 $\mathrm{A}, \mathrm{C} \alpha$ to $\mathrm{C} \alpha$ movement) onto the apical surface of the engaged HAA inhibitor.

Owing to the overlap with the RNase-active site (three of four invariant active site residues are exploited in the HAA-binding interaction), the HAA-binding pocket is highly conserved (Supplementary Fig. 3d) with only a conservative substitution of tyrosine for phenylalanine at position 889 differentiating the binding pocket between fungal and metazoan enzymes (Supplementary Fig. 4). This may explain the general crossreactivity of HAA inhibitors across IRE1 $\alpha$ orthologues tested (yeast, mouse and human) ${ }^{41}$.

Conserved interactions across the three co-structures that are predicted to contribute to affinity and specificity of the HAA inhibitor class include: a Schiff base interaction between the HAA aldehyde group and the amine group of Lys907; a hydrogen-bond interaction between the HAA hydroxy group and the side chain of Tyr892; pi-stacking of the Phe889 side chain with the apical surface of the HAA aromatic ring directly harbouring the hydroxy and aldehyde groups; and finally, pi-stacking of the His910 side chain with the basal surface of flanking HAA aromatic rings. All three co-crystallized HAA inhibitors possessed methoxy moieties at a position immediately adjacent to the core hydroxy moiety, and these possess the capacity to hydrogen bond with the side chain of Asn906. Since the methoxy moiety is not a conserved feature of all HAA inhibitors ${ }^{41-43}$, this interaction is not a general feature of the HAA inhibitor-binding mode.

Reflecting differences in chemical scaffold and substituent structure, each HAA inhibitor also made a limited number of distinct interactions with the binding pocket on IRE1 $\alpha$ that may account for differences in potency. These unique interactions were accommodated in part by plasticity of the binding mode evident by a subtle $(\sim 1.5 \AA)$ lateral shift of the single ring core of 
a

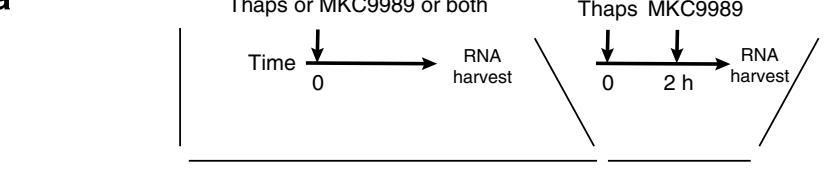

Thapsigargin -

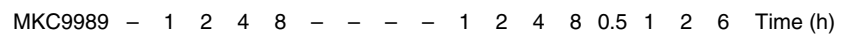
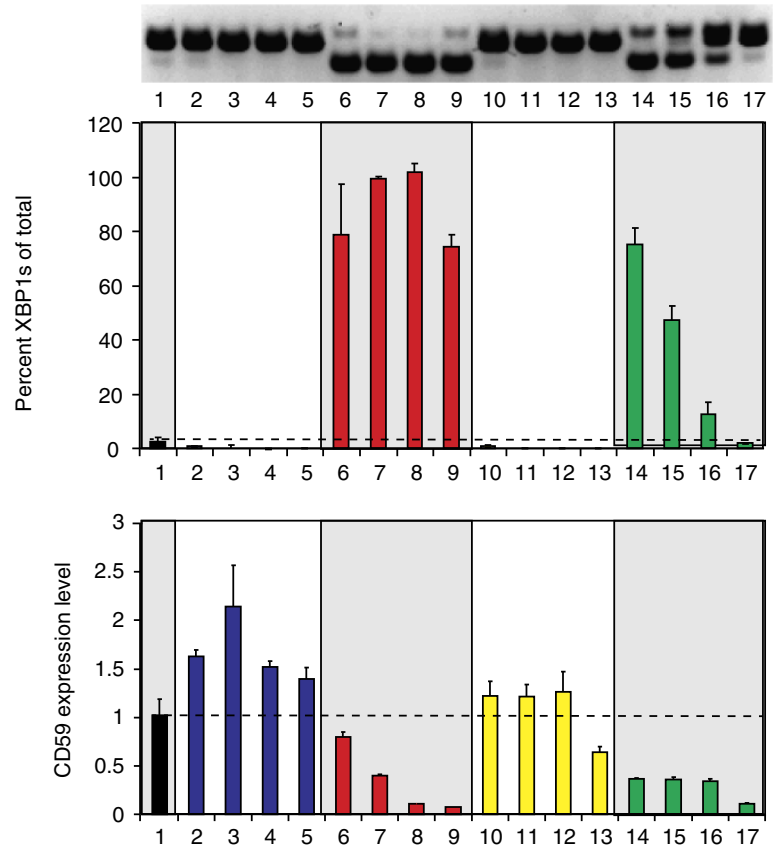

b

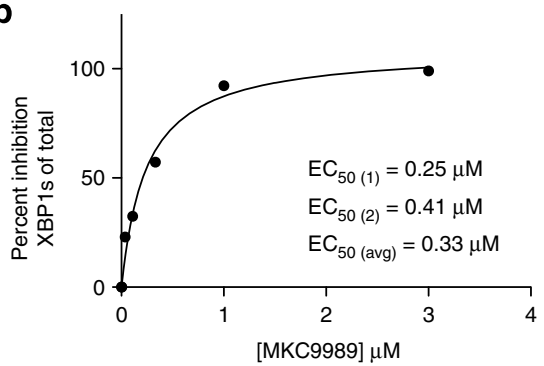

Figure 2 | Inhibition of IRE1 $\alpha$ function by MKC9989 in human RPMI 8226 plasmacytoma cells. (a) Time course analysis of MKC9989 inhibitory function on XBP1 splicing: reverse transcription PCR PAGE analysis (top) and quantification (middle) of XBP1-spliced products from three independent experiments shown as \pm s.e.m. Quantification of CD59 transcript levels from the same RNA samples (bottom). (b) Dose-response analysis of MKC9989 treatment on XBP1 splicing in human RPMI 8226 plasmacytoma cells. Shown is a representative profile with $\mathrm{EC}_{50}$ calculated as the average of two independent experiments.

OICR464 and OICR573 relative to that of the planar fused ring core of MKC9989 (Supplementary Fig. 3d). Unique interactions exploited by MKC9989 include: hydrogen bonds between Lys907 and the oxygen heterocycle of the coumarin ring and between Tyr892 and the oxygen atom of the ether moiety at position 3; van der Waals contacts involving the main chain Glu913 and the side chains of Pro915 and Leu914 with the coumarin $\mathrm{C}=\mathrm{O}$ group; and finally a hydrophobic interaction between the Phe889 side chain and the flexible polyether moiety at position 7 (Fig. 3b,d). These inhibitor-specific interactions may account for enhanced potency of MKC9989 relative to OICR464 and OICR573.
The aldehyde moiety of HAA inhibitors has been shown to selectively form a reversible Schiff base interaction with Lys 907 in the RNase domain and to a lesser degree with Lys599 in the ATP-binding site of the kinase domain, versus 20 other surfaceexposed lysine residues within the dual catalytic region of human IRE $1 \alpha^{43}$. This reactivity can be rationalized by the position of the Lys907 side chain at the back of a sheltered binding pocket. Due to the clamping action of the Phe889, His910 and Asn906 side chains on either side of the HAA planar ring structure, the Schiff base interaction once formed would be shielded from attack by water. Furthermore, reactivity of the aldehyde towards Lys 907 may be enhanced by the electron polarizing hydrogen bond between Tyr892 and the adjacent hydroxy moiety. These features are uniquely supported by the environment around Lys 907 . The fact that Lys599 displays some reactivity to HAAs may be explained by the sheltered environment of the kinase-active site, which would also shield a Schiff base interaction from attack by water once formed. Using kinase inhibition as a proxy for kinase domain engagement, the interaction of MKC9989 and OICR464 with the kinase-active site Lys599 is $\sim 10$ - to 100 -fold weaker than engagement with Lys907, whereas OICR573 does not appear to engage Lys599 to a detectable degree (Fig. 1c).

Basis for non-competitive mechanism of action. To discern how HAA inhibitors act non-competitively with respect to RNA substrate $^{41,43}$ while exploiting direct contacts to three of four invariant RNase-active site residues, we modelled a dinucleotide substrate into the active site region of IRE1 $\alpha$ bound to MKC9989. As transfer RNA (tRNA) endonuclease, whose X-ray crystal structure was determined in complex with $\mathrm{RNA}^{47}$, shares a highly similar active site architecture and inferred catalytic mechanism with IRE1 (ref. 11), it provided an instructive template for modelling the IRE1 $\alpha-$ RNA substrate-HAA inhibitor complex (see Methods for modelling details). As modelled in Supplementary Fig. 3e, MKC9989 binds immediately opposite to the RNA along an axis linking Asn906, His910 and Arg902 side chains, without overt clashes. His 910 has been proposed to act as a general acid that protonates the $5^{\prime}-\mathrm{OH}$ leaving group, whereas Arg905 and Asn906, the latter supported by a hydrogenbonding interaction with Tyr892, likely serve to position the scissile phosphate for nucleophilic attack. We reason that subtle changes to the position of three (His910, Asn906 and Tyr892) of these four conserved catalytic residues imposed by HAA inhibitor binding (Supplementary Fig. 3c) may be responsible in part for the resultant loss in RNase catalytic function. A more detailed understanding of HAA inhibitor mechanism of action awaits the determination of comparative structures of IRE $1 \alpha$ productively bound to RNA and non-productively bound to both RNA and HAA inhibitor.

Mutational analysis of the HAA-binding pocket. To explore HAA binding determinants on the RNase domain of IRE $1 \alpha$, we mutated the contact residues Phe889, Tyr892, Asn906, His910 and Lys907 in the context of a longer dual catalytic fragment of IRE1 $\alpha$ encompassing residues 499-977 (Fig. 4a). Consistent with their immediate proximity to the RNase-active site, all five mutations abolished RNase activity against a single hairpin substrate (Fig. 4b) while leaving protein kinase activity largely intact (Fig. 4c). This limited our ability to infer the effect of mutations on inhibitor binding by the analysis of enzymatic inhibition constants $\left(K_{\mathrm{i}}\right)$. However, using 600 -fold higher concentrations of a double hairpin substrate produced in T7 RNA runoff reactions and 10,000-fold higher concentrations of IRE1 $\alpha$, the Lys907Ala and Phe889Ala but not His910Ala, Tyr892Ala and Asn906Leu mutants displayed detectable RNase activity. In contrast to the 
a

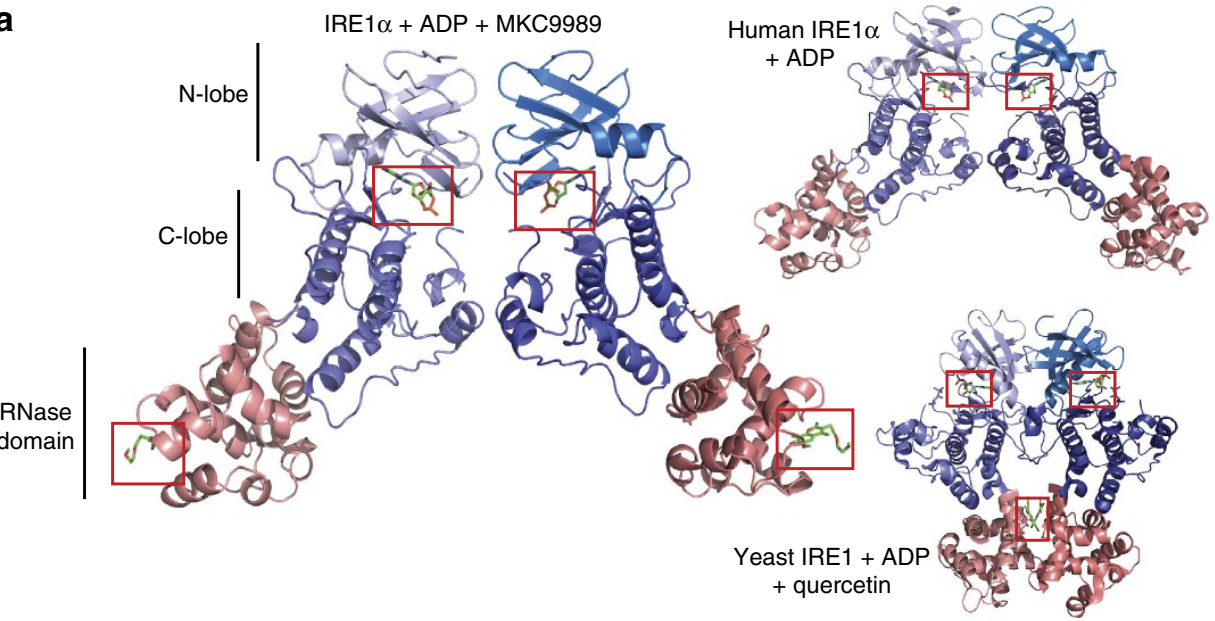

b
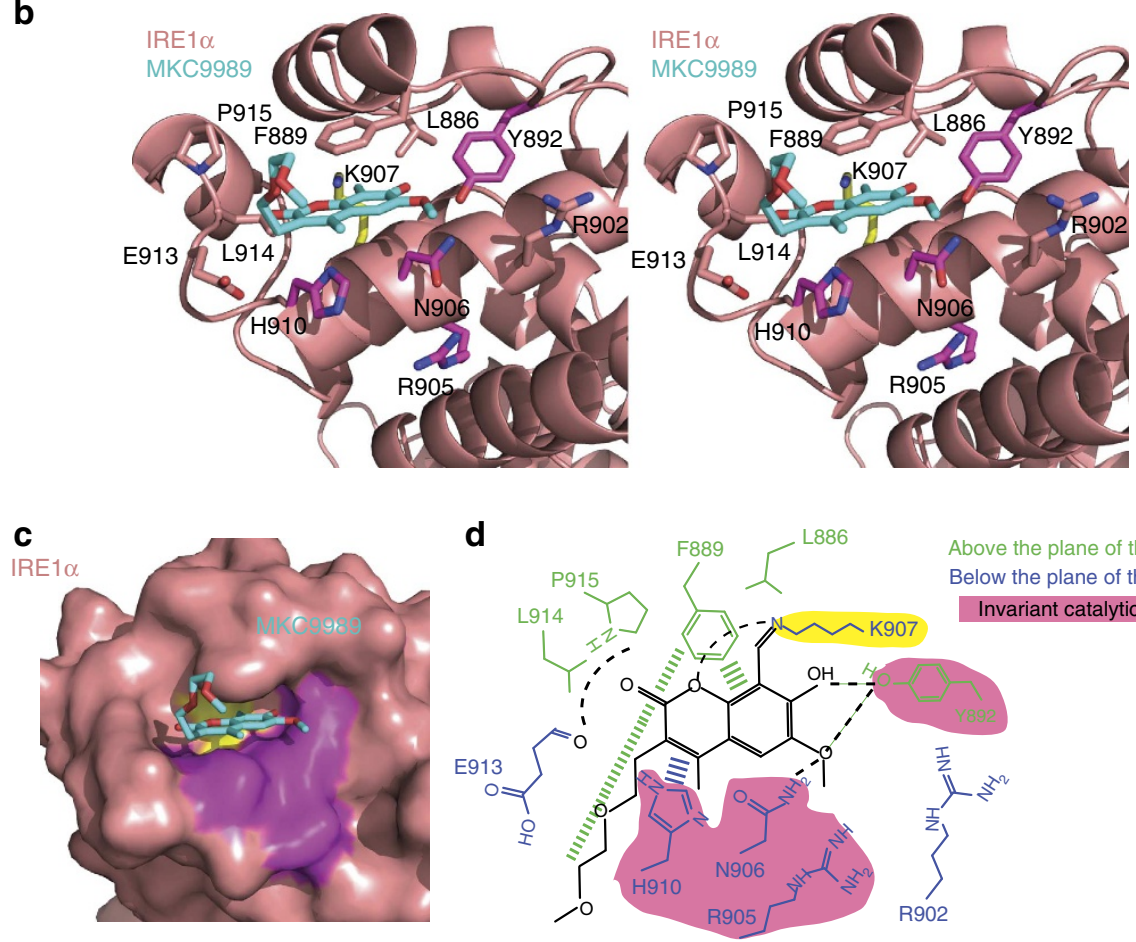

Figure 3 | Crystal structure of IRE1 $\alpha$ bound to MKC9989. (a) Ribbons representation of a face-to-face dimer configuration of IRE1 $\alpha$ in complex with $\mathrm{Mg}^{2+} / \mathrm{ADP}$ and MKC9989. ADP engaging the kinase-active site and MKC9989 engaging the RNase-active site are shown as sticks and highlighted by red boxes. For comparison, the dimer configurations adopted by human IRE1 $\alpha$ (PDB 3P23) and yeast IRE1 (PDB 3LJO) are shown at right. (b) Ribbons' stereo representation of MKC9989 engaging the RNase-active site of IRE1 $\alpha$. Invariant active site residues, Lys 907 and other conserved residues in the binding pocket are coloured purple, yellow and pink, respectively. Lys907 forms a Schiff base to the aldehyde moiety of MKC9989. (c) Zoom in surface view of the IRE1 $\alpha$-MKC9989 complex coloured as in b. (d) Schematic of contact residues and notable interactions mediating MKC9989 binding to IRE1 $\alpha$.

wild-type enzyme, the Lys907Ala but not the Phe889Ala mutant was insensitive to MKC9989 when assayed under these conditions (Fig. 4d).

Direct binding measurements using microscale thermophoresis revealed a close correlation between IRE1 $\alpha$-binding activity and inhibitor potency, with MKC9989 binding more tightly than OICR464 and OICR573 (Supplementary Fig. 5a, $K_{\mathrm{d}}=0.84$, 15.9 and $35.2 \mu \mathrm{M}$, respectively). Notably, the IRE1 $\alpha$ mutations Tyr892Ala $\left(K_{\mathrm{d}}=10 \mu \mathrm{M}\right)$, Asn906Leu $\left(K_{\mathrm{d}}=8.9 \mu \mathrm{M}\right)$, His910Ala $\left(K_{\mathrm{d}}=5.3 \mu \mathrm{M}\right)$ and Phe889Ala $\left(K_{\mathrm{d}}=10.9 \mu \mathrm{M}\right)$ perturbed the binding to MKC9989 minimally by 10-fold, while the IRE1 $\alpha$ Lys907Ala mutation abolished detectable binding (Supplementary Fig. 5b). Together, these results demonstrated the importance of protein interactions visualized in the IRE1 $\alpha-$
HAA inhibitor co-structures and highlighted the pre-eminent role for the Schiff base interaction with Lys907 in the HAA inhibitor mechanism of action.

Structure-activity relationships. To unify our understanding of SAR data as well as validate the binding mode observed in the HAA co-structures, we assembled an HAA analogue series around a naphthalene scaffold ${ }^{42}$ (WO 2008/154484 A1; WO 2011/056744 A1) (Fig. 5). This series offered the advantage of more sites around the dual fused ring core for addition of substituents, while the chemical space largely overlaps with the biphenyl and coumarin HAA inhibitors. In keeping with chemical convention, we used a substituent numbering scheme 
a

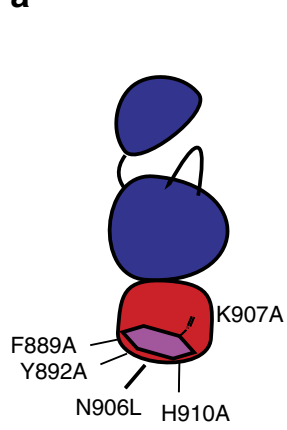

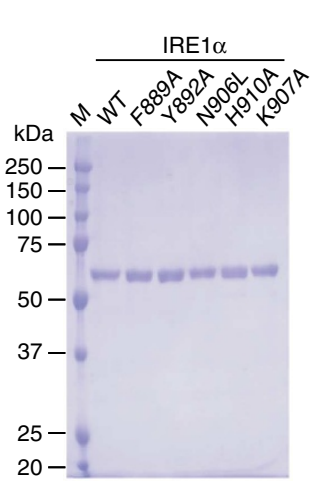

c

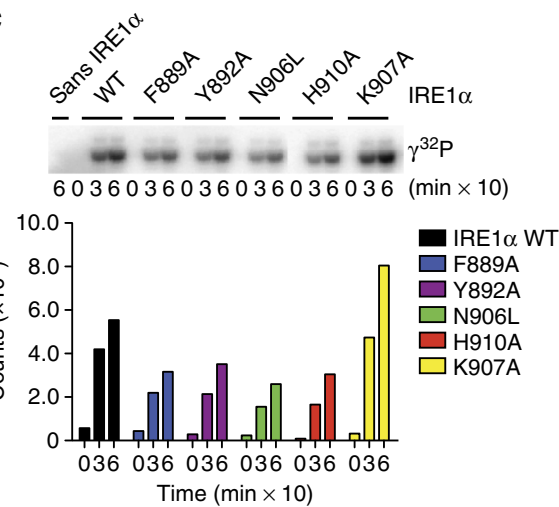

b

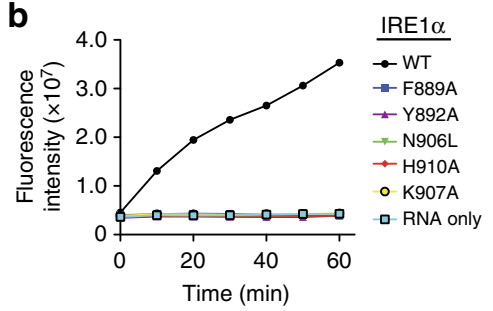

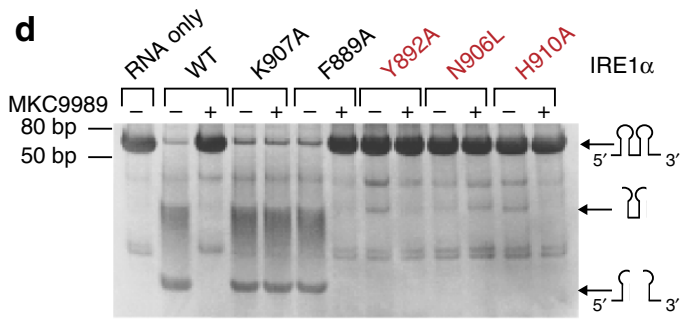

Figure 4 | SAR of HAA inhibitors and their binding site on IRE1 $\alpha$. (a) Schematic (left) and SDS-PAGE analysis (right) of IRE1 $\alpha$ RNase-active site mutants. (b) Effect of RNase-active site mutations on IRE1 $\alpha$ RNase function as assessed by a real-time fluorescence readout assay. (c) Effect of RNase-active site mutations on IRE1 $\alpha$ kinase function as assessed by auto-kinase activity (phosphor image, top; quantification, bottom). (d) Sensitivity of IRE1 $\alpha$ wild-type (WT) and RNase-active site mutants to inhibition of RNase activity by MKC9989 as assessed using a dual-hairpin RNA substrate.

with position 1 corresponding to the aldehyde moiety and position 2 proceeding along the direction of the adjacent hydroxy moiety (MKC3437). Consistent with previous findings for a single aryl ring scaffold ${ }^{41}$, substitution of the aldehyde or hydroxy moieties at positions 1 and 2 were not tolerated (MKC3964 and MKC3820). This likely reflected the importance of the Schiff base interaction with Lys907 and the hydrogen bond interaction with Tyr892, respectively. In accordance with position 3 and 7 facing towards solvent, addition of bulky substituents (MKC3426 and MKC3946) were well tolerated. Substitutions at position 8 were more restrictive owing to the partially buried nature of the interaction site with IRE1 $\alpha$. Addition of a bromine substituent at this position (MKC3987) was favoured relative to hydrogen $\left(\mathrm{IC}_{50}=0.39\right.$ versus $2.2 \mu \mathrm{M}$, respectively), while a bulkier methylpiperizine-carbonyl-phenyl group was disfavoured (MKC4027) $\left(\mathrm{IC}_{50}=5.7 \mu \mathrm{M}\right)$. Like the $\mathrm{C}=\mathrm{O}$ group of the coumarin scaffold of MKC9989, bromine at position 8 would be accommodated in the narrow confines of the binding site. In contrast, the methylpiperizine-carbonyl-phenyl group is predicted to sterically clash in the absence of a major shift in inhibitor-binding mode. In summary, these SARs are consistent with the inhibitor-binding mode elucidated by X-ray co-structure and molecular modelling analyses and suggest further avenues for future optimizations.

ADP as a model for dimer-breaking IRE1 $\alpha$ RNase inhibitors. Back-to-back dimerization and subsequent polymerization of the fused kinase endoribonuclease catalytic module is required for the RNase activity of yeast IRE1 (ref. 11) and presumably all orthologues. The binding of nucleotide and small molecule protein kinase inhibitors to the kinase domain can influence dimer/oligomer formation and as a result RNase activity; ADP, janus kinase (JAK) inhibitor I, cyclin-dependent kinase inhibitor I and APJ (N $2 \sim-1 \mathrm{H}$-benzimidazol-5-YL-N $\sim 4 \sim$-(3-cyclopropyl$1 \mathrm{H}$-pyrazol-5-YL)pyrimidine-2,4-diamine) promoted the dimerization/oligomerization of yeast IRE1 and concomitantly its RNase activity $^{37,38,40}$, whereas compound 3 (1-(4-(8-amino-3-isopropy- limidazo[1,5-a]pyrazin-1-yl)naphthalen-1-yl)-3-(3-(trifluoromethyl) phenyl)urea) inhibited the dimerization/oligomerization of human IRE1 $\alpha$ and concomitantly its RNase function ${ }^{39}$. We posit that the structure of murine IRE1 $\alpha$ reported here and human IRE1 $\alpha$ reported previously, which do not adopt the back-to-back dimer configuration reflective of the 'RNase-active' state, provides insight into how in general dimer-breaking agents might act.

Contrary to the expectation based on its effect on yeast IRE1, we discovered that ADP is an inhibitor of both the RNase and dimer/oligomerization activities of murine IRE1 $\alpha$ in vitro. As assessed by velocity analytical ultracentrifugation, in the absence of ADP, IRE1 undergoes concentration-dependent oligomerization (Fig. 6a). Addition of ADP (Fig. 6a) and JAK inhibitor I (Fig. 6a) antagonized and enhanced this behaviour, respectively (see Fig. 6b for chemical structures). Consistent with these effects on oligomerization, $\mathrm{ADP}$ inhibited $\left(\mathrm{IC}_{50}=117 \mu \mathrm{M}\right)$ and JAK inhibitor I activated $\left(\mathrm{EC}_{50}=0.19 \mu \mathrm{M}\right)$ murine IRE1 $\alpha$ RNase function in vitro (Fig. 6c,d). JAK inhibitor I exerted its influence on yeast IRE1 by engaging the kinase-active site $^{40}$, and consistent with a common site of action on murine IRE1 $\alpha$, JAK inhibitor I potently inhibited auto-kinase activity with an $\mathrm{IC}_{50}$ of $1.1 \mu \mathrm{M}$ (Fig. 6e). Supporting the notion that murine IRE1 $\alpha$ samples the same back-to-back dimer and higher-order polymer configurations demonstrated for yeast IRE1, murine IRE1 $\alpha$ oligomerization was similarly dependent on (1) the N-terminal region preceding the kinase domain (Fig. 6a), (2) the integrity of the back-to-back dimer interface as assessed by a Asp620Ala mutation (Fig. 6a) and (3) enzyme phosphorylation status (Fig. 6a). Confirming the predicted importance of the yeast IRE1 back-to-back dimer configuration for murine IRE1 $\alpha$ RNase function, dimer interface mutations in murine as shown for yeast IRE1 (ref. 11) also perturbed the RNase but not the kinase functions of murine IRE1 $\alpha$ (Fig. 6f,g). These findings demonstrated that many of the regulatory features discerned for yeast IRE1 were general to murine IRE1 $\alpha$ with the exception of the specific response to ADP. The findings further suggested 
<smiles></smiles><smiles>O=Cc1cccc2ccccc12</smiles>

MKC3964<smiles>CC(=O)c1c(O)ccc2ccccc12</smiles>
МKC3820

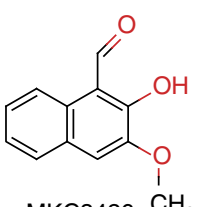
MKC3426 $\mathrm{CH}_{3}$<smiles>CN1CCN(C(=O)c2ccc(-c3ccc4c(C=O)c(O)ccc4c3)s2)CC1</smiles><smiles>O=Cc1c(O)ccc2ccc(Br)cc12</smiles>

MKC3987<smiles>CN1CCN(C(=O)c2ccc(-c3ccc4ccc(O)c(C=O)c4c3)cc2)CC1</smiles>

MKC4027
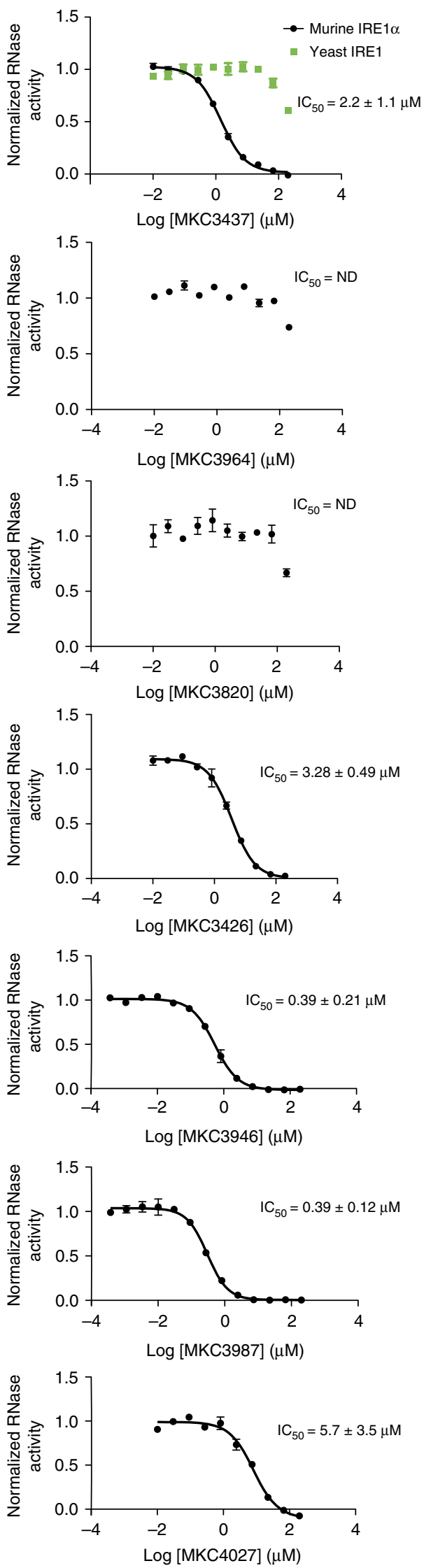

Figure 5 | SAR analysis of a naphthalene analogue series on IRE1 $\boldsymbol{\alpha}$ RNase activity. Shown are analogue structures (left) and RNase inhibition profiles (right). IC 50 values represent the average for $n=4$ (two experiments performed in duplicate) \pm s.d. Displayed profiles represent one experiment performed in duplicate. Substituent numbering scheme and RNase inhibitory activity against yeast IRE1 are shown on top for the minimal naphthalene scaffold MKC3437. 


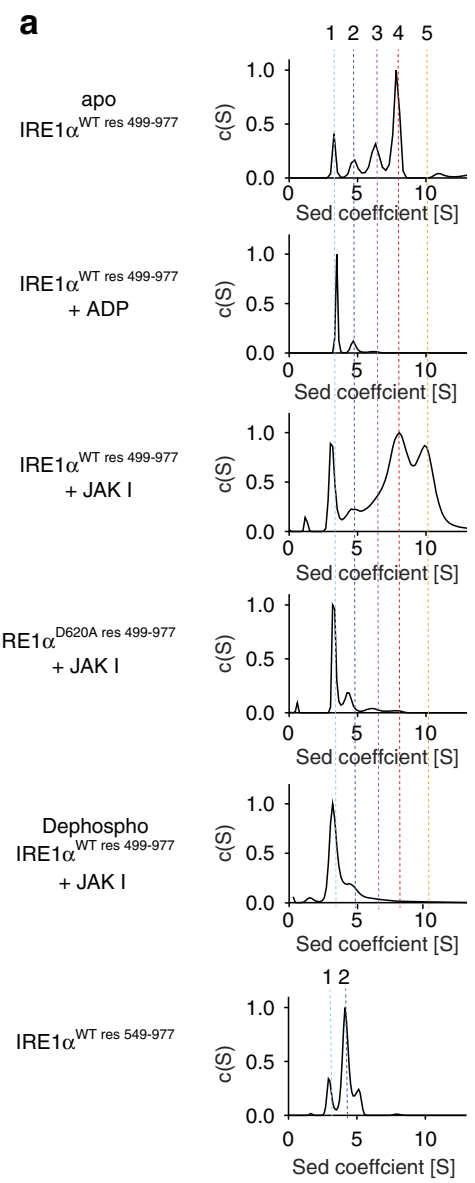

C
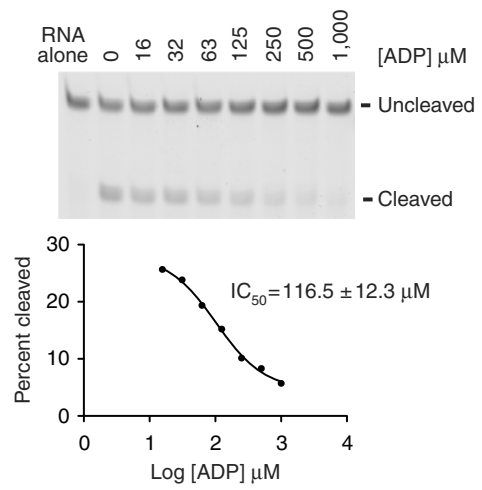

d

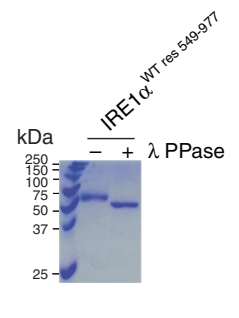

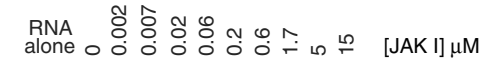

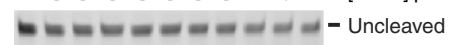

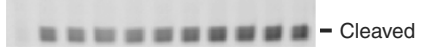

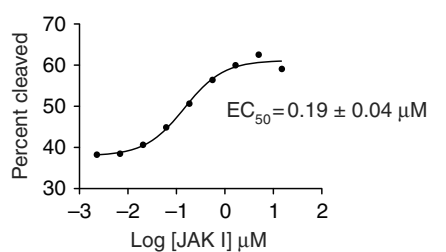

e
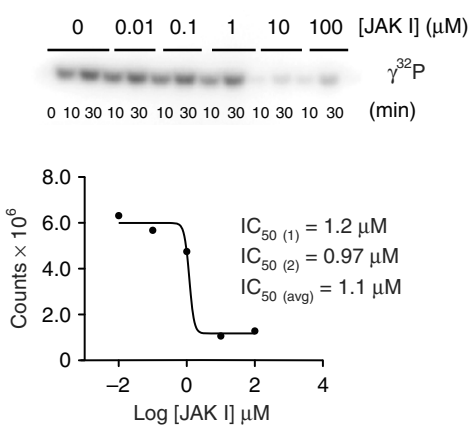

g

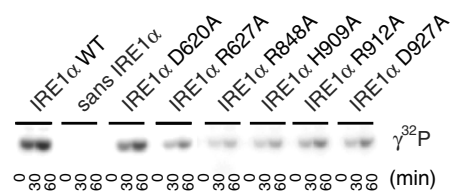

f<smiles>Nc1ncnc2c1ncn2C1OC(COP(=O)(O)OP(=O)(O)O)C(O)C1O</smiles><smiles>CC(C)(C)c1nc2c3ccc(F)cc3c3c(=O)[nH]ccc3c2[nH]1</smiles>

০

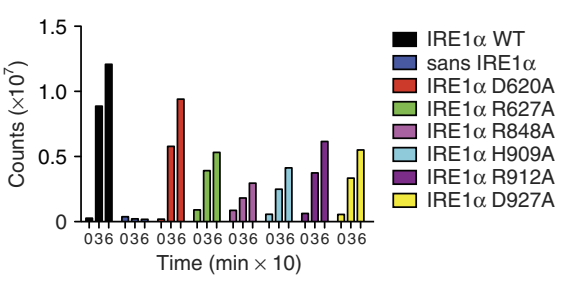

Figure 6 | Effects of kinase domain active site binders on murine IRE1 $\alpha$ function. (a) Analysis of oligomerization status. Velocity analytical ultracentrifugation analyses were performed on murine IRE1 $\alpha$ preparations (labelled on left) at $18 \mu \mathrm{M}$ protein concentration. See Supplementary Fig. 6 for full protein concentration series. ADP and JAK inhibitor I concentrations were 500 and $30 \mu \mathrm{M}$, respectively. SDS-PAGE analysis of murine IRE $\alpha$ pre- and post-treatment with lambda phosphatase is shown in the right panel. (b) Chemical structures of ADP and JAK inhibitor I. (c) Effect of ADP on the RNase activity of murine IRE1 $\alpha$ using a model single-hairpin substrate labelled with fluorescein. Reaction products were separated via PAGE, detected using a GE Healthcare Typhoon Variable Mode Imager (top panel) and quantified using ImageQuant 5 software (bottom panel). Shown is a representative profile. $I C_{50} \pm$ s.d. was calculated for $n=3$. (d) Dose-response analysis of JAK inhibitor I on the RNase activity of murine IRE $1 \alpha$ assayed as in c. Shown is a representative profile. $E_{50} \pm$ s.d. was calculated for $n=3$. (e) Dose-response analysis of JAK inhibitor I on the auto-kinase activity of murine IRE1 $\alpha$ as assessed using P $^{32}-\gamma$-ATP. Quantification plot presented in lower panel represents the 10 min time point from auto-radiographs in the top panel. Shown is a representative profile. $I C_{50}$ was calculated for $n=2$ (two experiments performed in singlicate). (f) Effect of the indicated back-to-back dimer interface mutations on murine IRE1 $\alpha$ RNase function, as assayed in Fig. 1b. (g) Effect of the indicated back-to-back dimer interface mutations on murine IRE1 $\alpha$ auto-kinase function (phosphor image, top; quantification, bottom), as assayed in Fig. 1c. 


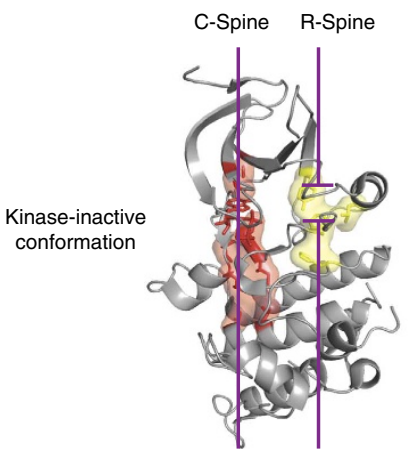

Murine IRE $1 \alpha+$ ADP + MK9989 Murine IRE $1 \alpha+$ ADP + OICR573 Murine IRE $1 \alpha+$ ADP + OICR464 Human IRE1 $\alpha+\operatorname{ADP}(3 P 23)$

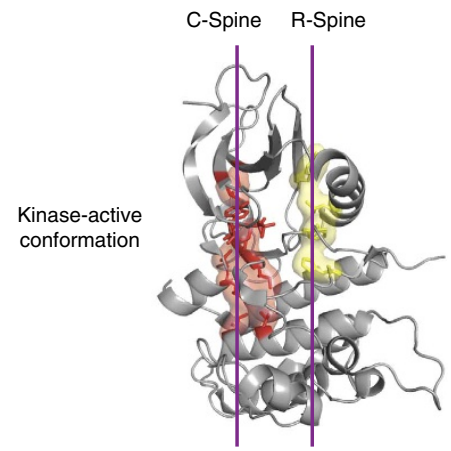

Yeast IRE1 + ADP (2RIO)

Yeast IRE1 + ADP + quercetin (3LJ0)

Yeast IRE1 + ADP + JAK inhibitor I (3LJ2)

Yeast IRE1 + ADP + CKD1/2 inhibitor I (3LJ1)

Yeast IRE1 APO (3SDM)

Yeast IRE1 + APJ (3FBV)

b

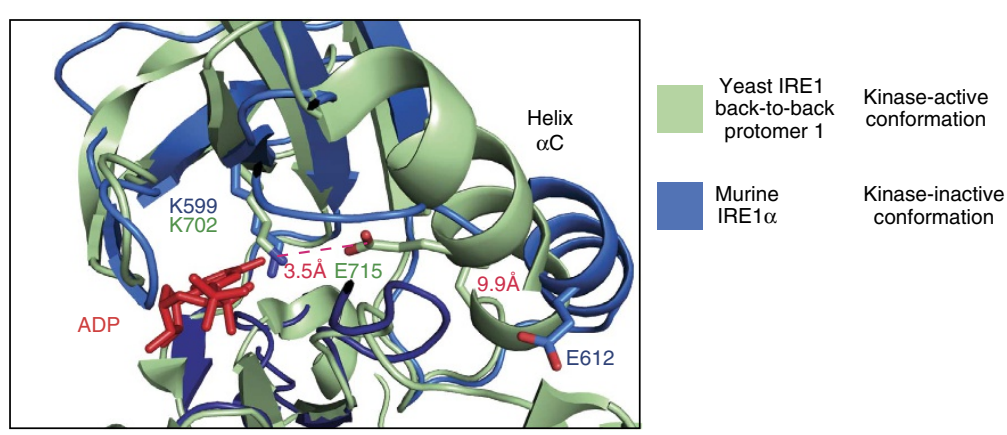

C

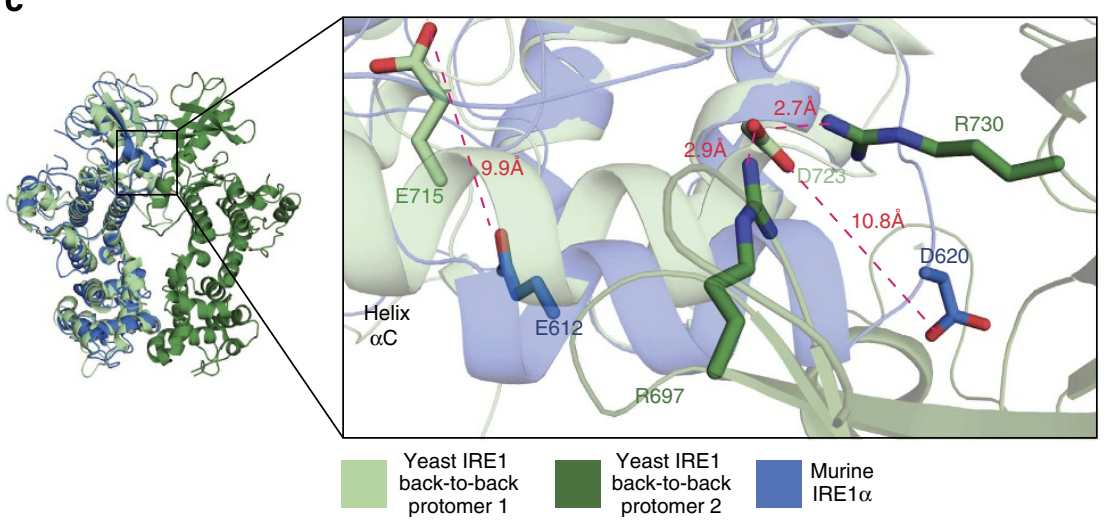

Figure 7 | Structure analysis of the kinase domain of murine IRE1 $\alpha$. (a) Ribbons' representation of IRE1 $\alpha$ kinase domains highlighting regulatory (yellow) and catalytic (red) spine alignments. All yeast structures solved to date display productive alignment of spines (right), while HAA-bound murine IRE1 $\alpha$ structures and the dephospho-human IRE1 $\alpha$ structure adopt non-productive alignments of the regulatory spine. PDB code and the respective ligand engaging the kinase-active site are indicated. (b) Zoom-in view of the kinase-active site of murine IRE1 $\alpha$ superimposed on yeast IRE1 (PDB 2RIO)

highlighting the displaced position of helix $\alpha$ C. (c) Zoom-in view of the projected back-to-back dimer interface of murine IRE1 $\alpha$ (only one protomer shown) superimposed on the yeast IRE1 back-to-back dimer (PDB 2RIO) highlighting the physical link between helix $\alpha \mathrm{C}$ and the back-to-back dimer interface. Side chains composing an essential intra-dimer salt bridge and the subdomain III glutamate side chain are shown as sticks.

that the crystal structure of murine IRE1 $\alpha$ bound to ADP might provide a useful platform to discern the basis by which dimer-breaking inhibitors of IRE1 RNase function act.

The kinase domain of murine IRE1 $\alpha$ possessed a prototypical bilobal architecture consisting of an $\mathrm{N}$-lobe rich in $\beta$-strands and a single regulatory helix $\alpha \mathrm{C}$, and a C-lobe composed predominantly of $\alpha$-helices. In their active states, protein kinase domains can sample a closed conformation that aligns parallel regulatory and catalytic spines to productively bind and coordinate ATP within the inter-lobe cleft and to facilitate the phosphotransfer reaction ${ }^{48}$. The murine IRE1 $\alpha$ kinase domain is notable in adopting a 'kinase-inactive' conformation in which the catalytic spine is intact but the regulatory spine is disrupted (Fig. 7a, left panel). The catalytic spine, consisting of N-lobe residues Val586, Ala597 and the adenine ring of ADP, and C-lobe residues Leu649, Ile694, Leu695, Leu696, Val763 and Val767, forms a continuous hydrophobic column that spans the vertical length of the kinase domain. The regulatory spine in contrast, consisting of the N-lobe residues Leu616 and Tyr628 and the C-lobe residues His686 and Phe712, forms a broken hydrophobic column partitioned midway by a mispositioned Leu616 side chain, which projects from a non-productive, laterally displaced helix $\alpha \mathrm{C}$. A non-productive orientation of helix $\alpha \mathrm{C}$ also manifests a loss of the ATPcoordinating salt bridge between the kinase domain invariant 
residues Lys599 (subdomain II) and Glu612 (subdomain III). Specifically, a 9-Å lateral shift of Glu612 prohibited the close ( $\cong 3.5 \AA$ ) interaction with Lys599 observed for the corresponding residues in yeast 'kinase-active' IRE1 structures (Fig. 7b). These two non-productive features of the murine IRE1 $\alpha$ kinase domain are shared with the human IRE1 $\alpha$ kinase domain structure also bound to $\mathrm{ADP}^{46}$, and differ from all yeast IRE1 co-structures bound to dimer promoting small molecule effectors (Fig. 7a, right panel).

The non-productive orientation of helix $\alpha \mathrm{C}$ is notable as helix $\alpha \mathrm{C}$ forms an integral component of the back-to-back dimer interface of 'RNase-active' yeast IRE1 structures ${ }^{11,37}$ and may provide a link between ligand binding to the kinase-active site and back-to-back dimerization. IRE1-invariant residues Arg697, Asp723 and Arg730 in yeast IRE1 (corresponding to Arg594, Asp620 and Arg627 in murine IRE1 $\alpha$ ) form an essential threecentre salt bridge across the back-to-back dimer interface (Fig. 7c) that is required for the RNase function of both yeast ${ }^{11}$ and murine (Fig. 6f) enzymes. In the murine IRE1 $\alpha$ structure, the lateral shift in helix $\alpha \mathrm{C}$ displaces Asp620 $10.8 \AA$ from the required position to interact with Arg594 and Arg627 (Fig. 7c). Since the three-centre intermolecular salt bridge is essential for the back-toback dimerization and RNase function of murine IRE1 $\alpha$ (Fig. 6a,f), we reason that the non-productive conformation of helix $\alpha \mathrm{C}$ is responsible for the decreased propensity of murine IRE1 $\alpha$ to adopt the back-to-back dimer configuration when bound to ADP.

\section{Discussion}

Our studies reveal how HAA inhibitors engage the RNase-active site of IRE1 $\alpha$ with high affinity and specificity by exploiting a shallow complementary pocket and an essential Schiff base interaction between the aldehyde moiety of the inhibitor and the side chain amino group of Lys907. The presented HAA costructures allow for a rationalization of current SAR and provide a platform for further rounds of optimization to improve inhibitor potency, bioavailability and selectivity.

Interestingly, despite the fact that the HAA contact residues in IRE1 $\alpha$ are highly conserved, yeast IRE1 is relatively resistant ( 100-fold) to the fused dual-ring core of MKC9989, whereas it is equally sensitive to the single-ring core of OICR464 and OIRC573. This trend holds true also for the fused dual-ring core of the naphthalene scaffold (Fig. 5, first panel). As only a conservative substitution of Phe889 to tyrosine in yeast IRE1 differentiates the respective HAA-binding pockets, we speculate that this behaviour may be due to differences in binding pocket plasticity, which may be less accommodating for chemical scaffolds employing planar dual-ring cores in yeast IRE1.

As IRE $1 \alpha$ and $\beta$ human isoforms are $100 \%$ identical in the composition of HAA-binding pocket residues (Supplementary Fig. 4), we anticipate that both isoforms will be sensitive to inhibition by HAA inhibitors, although our findings with yeast IRE1 hold out the possibility for isoform selectivity despite similarities in binding pocket composition. The observation that HAA inhibitors centrally engage the RNase-active site by exploiting three of four invariant and essential catalytic residues for binding would explain their general effectiveness against both $X B P 1$ splicing and RIDD cleavage targets ${ }^{41,43}$. The exploitation of essential catalytic residues for binding may also impose a major impediment to the acquisition of resistance mutations if employed in a clinical setting, since mutations shown here that abrogate HAA binding also compromise IRE $1 \alpha$ RNase catalytic activity. Finally, RNase L, the sole paralogue of IRE1 $\alpha$ in mammals, notably lacks an appropriately positioned lysine residue for Schiff base formation (substituted for leucine in human RNase L) and shares only three of eight other contact residues (equivalent to the invariant catalytic residues Tyr892, Asn906 and His910 in human IRE1 $\alpha$ ). These differences likely account for the observed resistance of RNase L to HAA inhibitors ${ }^{41,43}$.

Although the core scaffold and ring substituents of MKC9989 make no overt clash with RNA, substitutions at position 3 with far bulkier groups have great potential to hinder RNA binding through clashes with the scissile phosphate group. Such substitutions would be expected to cause a transition of an HAA analogue from a substrate non-competitive to a substrate competitive mechanism of action. We speculate that elaboration of HAA inhibitor structure to exploit the RNA substrate-binding infrastructure (for example, by covalently linking an HAA to a dinucleotide mimetic), to impart a competitive mechanism of action, may also provide a means to improve inhibitor potency further. By capturing favourable or disfavourable interactions with specific RNA substrates, it may also be possible to engineer HAA analogues with inhibitory properties that discriminate between the numerous XBP1 and RIDD substrates.

Small molecule binders to the kinase domain of IRE1 that support a non-productive outwardly displaced conformation of helix $\alpha \mathrm{C}$, as promoted by ADP in the human and mouse IRE1 $\alpha$ crystal structures, will function as protein kinase inhibitors by virtue of competitively inhibiting ATP binding, but might also function as RNase inhibitors by preventing attainment of the productive back-to-back dimer configuration required for RNase activity. As such, the crystal structures of mouse and human IRE1 $\alpha$ would provide useful platforms for the design of small molecule kinase inhibitors that repress RNase function. Towards this end, we speculate that compound 3 (1-(4-(8amino-3-isopropylimidazo[1,5-a]pyrazin-1-yl)naphthalen-1-yl)-3(3-(trifluoromethyl)phenyl)urea), a first in class ATP-competitive protein kinase inhibitor that inhibits IRE1 RNase function ${ }^{39}$, might act through such a mechanism.

Biomolecules containing aldehyde moieties are common in both food stuffs, essential nutrients and vitamins, including vanilla, sugars (glucose) and vitamins $\mathrm{A}$ and $\mathrm{B}_{6}$. Although some aldehyde-containing compounds can form irreversible adducts, this is limited to unsaturated hydroxylated aliphatic chains such as lipid peroxidation products including 4-hydroxynonenal, which can induce ER stress ${ }^{49}$, or hydroxylated saturated aliphatic chains where an Amadori rearrangement is required after the imine is formed. This is the case of HbAlc generation by glucose on haemoglobin ${ }^{50}$, the major biomarker of long-term glucose exposure in diabetics. Aromatic aldehydes including pyridoxal phosphate (vitamin $\mathrm{B}_{6}$ ) are unable to undergo such conversion. Furthermore, Schiff bases are not stable in the presence of water and studies indicate that dissociation from the mammalian IRE1 $\alpha$ is rapid both on the enzyme in vitro and in cells after washout ${ }^{41,43}$. Therefore, stable adduct formation and creation of new epitopes by lysine conversion are not likely for IRE1 or other proteins limiting the possibility of immune recognition and sensitization in vivo; however, transient adduct formation of buried lysines in heterologous enzymes cannot be formally ruled out. HAA compounds designed to enhance the oxygen saturation of haemoglobin have long serum half-lives and excellent target-binding properties in humans $s^{51}$, contrary to conventional wisdom. Indeed, HAA inhibitors of IRE1 $\alpha$ are active and well-tolerated in vivo; first, the biphenyl HAA analogue, compound 2, synergized with an oncolytic virus ${ }^{44}$, second, the naphthalene compound MKC3946 was readily tolerated with high exposure where it inhibited the splicing of XBP1 mRNA in tissues and tumours and reduced myeloma tumour growth ${ }^{42}$ and finally, the coumarin compound $4 \mu 8 \mathrm{C}$ was effective in suppressing XBP1s, inflammatory cytokines and 
inflammation in a rheumatoid arthritis model ${ }^{52}$. These studies suggest that HAA compounds may be highly selective for the RNase-active site of IRE $1 \alpha$ and can be administered in vivo to obtain desired effects.

\begin{abstract}
Methods
XBP1 splicing and CD59 stability analysis. Human RPMI 8226 plasmacytoma cells were grown in monolayer culture using Dulbecco's modified Eagle's medium supplemented with $10 \%$ fetal calf serum at $37^{\circ} \mathrm{C}$ and $5 \% \mathrm{CO}_{2}$. MKC9989 was prepared as $10 \mathrm{mM}$ stocks in DMSO, stored at $-20^{\circ} \mathrm{C}$ and diluted in medium as indicated. Thapsigargin $(\mathrm{Tg})$ was resuspended in DMSO and diluted in medium. Cells were grown to $50 \%$ confluency, treated with $1 \mu \mathrm{M}$ Tg and/or $10 \mu \mathrm{M}$ MKC9989 at the indicated time points. Following incubation of cells for the indicated periods, cells were collected. Procedures for preparation and measurement of XBP1s, XBP1u and CD59 mRNAs were as described previously ${ }^{41}$.
\end{abstract}

Protein expression and purification. Murine IRE1 $\alpha$ residues 499-977 used for in vitro biochemical and biophysical analyses and IRE1 $\alpha$ residues 549-977 used for $\mathrm{X}$-ray crystallographic analyses, both harbouring an Asn772Tyr substitution, were expressed in SF9 insect cells using the Bac-to-Bac baculovirus system (Invitrogen). IRE1 $\alpha$ fragments were cloned into pFastBac HTA vector as N-terminal polyhistidine tag fusions and viruses were generated according to manufacturer's instructions. Large-scale protein expression was performed from 81 cultures of SF9 cells grown in suspension. Following 3 days post infection, cells were collected by centrifugation, lysed by sonication in lysis buffer containing: $0.1 \mathrm{M}$ Tris $\mathrm{pH} 7.0,1 \mathrm{M}$ $\mathrm{NaCl}, 25 \mathrm{mM}$ imidazole, $1 \mathrm{mM}$ tris (2-carboxyethyl) phosphine (TCEP) and $10 \%$ glycerol, and purified by $\mathrm{Ni}$ immobilized-metal affinity chromatography. The polyhistidine tag was cleaved with Tobacco etch virus protease and subtracted by an additional immobilized-metal affinity chromatography step. Following sizeexclusion chromatography using a Superdex S200 column equilibrated in $25 \mathrm{mM}$ Hepes $\mathrm{pH} 7.0,0.5 \mathrm{M} \mathrm{NaCl}$ and $2 \mathrm{mM}$ TCEP, pure fractions were pooled and concentrated to $10 \mathrm{mg} \mathrm{ml}^{-1}$ and flash frozen in liquid nitrogen. Human IRE1 $\alpha$ residues 462-977 and yeast IRE1 residues 658-1,115 (with an internal deletion from Cys869 to Phe892) were expressed and purified as described previously ${ }^{11,41}$ In brief, yeast IRE1 was expressed from a pProEX plasmid in Escherichia coli BL21 cells as a polyhistidine-tagged fusion. Human IRE1 $\alpha$ was expressed using the Bac$\mathrm{N}$-Blue baculovirus system and SF9 insect cells as a GST-tagged fusion. Proteins were purified using Ni-nitrilotriacetic acid (NTA) and glutathione resin chromatography, respectively, followed by protease cleavage of the affinity tag and finally by size-exclusion chromatography on a Superdex S200 column.

Crystallization and structure determination. Complexes were preformed on ice for $30 \mathrm{~min}$ before crystallization. The final solution contained $200 \mu \mathrm{M}$ IRE $1 \alpha, 1 \mathrm{mM}$ inhibitor, $0.5 \%$ DMSO (v/v), $2 \mathrm{mM}$ ADP, $2 \mathrm{mM} \mathrm{MgCl}_{2}, 2 \mathrm{mM}$ TCEP, $25 \mathrm{mM}$ HEPES, pH 7.0. Crystals were grown at $20^{\circ} \mathrm{C}$ by mixing the preformed complex with precipitant solution containing $0.1 \mathrm{M}$ HEPES, 12\% PEG8000 and 8\% ethylene glycol at pH 7.5. Rod-shaped crystals $\sim 0.15 \mathrm{~mm}$ in length grew after a week, and were flash frozen in liquid $\mathrm{N}_{2}$ before data collection.

All data sets were processed using XDS ${ }^{53}$. Anisotropic truncation and scaling was applied using the UCLA MBI Diffraction Anisotropy Server (http:// services.mbi.ucla.edu/anisoscale) ${ }^{54}$. The structure of the IRE1 $\alpha$-MKC9989 complex was solved by molecular replacement using CCP4-PHASER ${ }^{55}$ and the structure of human IRE1 $\alpha$ (PDB 3P23 (ref. 46)) as the search model. The other HAA complexes were solved using the IRE1 $\alpha$-MKC9989 structure as the search model. All structures were refined using PHENIX Refine ${ }^{56}$. Real space inspection and refinement was performed using $\mathrm{COOT}^{57}$. $\mathrm{ADP}, \mathrm{Mg}^{2+}$ and the inhibitors were manually positioned in difference maps. Geometric restraints for the inhibitors were generated using eLBOW (PHENIX package) ${ }^{58}$. All inhibitors that were modelled were covalently bound to the Lys 907 through a Schiff base. For IRE1 $\alpha$-OICR573 and IRE1 $\alpha$-OICR464 structures, a long tubular density at the surface of one protein protomer was modelled as a PEG (polyethylene glycol) molecule.

Data sets for MKC9989, OICR573 and OICR464 co-structures were collected at $100 \mathrm{~K}$ at $0.979 \AA$ (NE-CAT beamline 24-ID-C), $1.540 \AA$ (home source) and $0.979 \AA$ wavelengths (NE-CAT beamline 24-ID-C), respectively. Ramachandran statistics corresponding to outliers, allowed and favoured regions for the MKC9989 co-structure were $0.79,6.9$ and $93.02 \%$, for the OICR573 co-structure were 0.33 4.09 and $95.58 \%$ and for the OICR464 co-structure were $0.47,4.93$ and $94.61 \%$, respectively.

In vitro kinase assays. Auto-phosphorylation kinase assay in Fig. 6e was performed with $1.5 \mu \mathrm{M}$ murine IRE1 $\alpha$ and $150 \mu \mathrm{M}$ ATP spiked with $27.7 \mathrm{nM}$ $\mathrm{P}^{32}-\gamma$-ATP. Reactions were pre-incubated with IRE $1 \alpha$ and inhibitor for $1 \mathrm{~h}$ at room temperature. After addition of ATP reaction mix, reactions were incubated at room temperature. Reactions were terminated by addition of SDS-polyacrylamide gel electrophoresis (PAGE) $6 \times$ loading buffer and analysed by SDS-PAGE using NuPage $4-12 \%$ Bis-Tris gels. $\mathrm{P}^{32}-\gamma$-ATP signal was detected by phosphor imaging using a GE Healthcare Typhoon Variable Mode Imager. Quantification was performed using ImageQuant5 software. Trans auto-phosphorylation assays in Figs $1 \mathrm{c}, 4 \mathrm{c}$ and $6 \mathrm{~g}$ were performed as above, except with $150 \mathrm{nM}$ of IRE $1 \alpha$ and $15 \mu \mathrm{M}$ of kinase dead (Asp797Ala) yeast IRE1, residues 658-1115, as a phosphoacceptor substrate.

Endoribonuclease assays. Fluorescence-based RNA cleavage assays were performed with $10 \mathrm{nM}$ IRE1 $\alpha$ protein and $100 \mathrm{nM}$ of a single hairpin RNA substrate ( $5^{\prime}$-CAUGUCCGCAGCGCAUG- $\left.3^{\prime}\right)$, labelled on the $5^{\prime}$ and $3^{\prime}$ termini with Alexa Fluor 647 fluorophore and black hole quencher, respectively. Reaction buffer consisted of $50 \mathrm{mM}$ Tris pH 7.0, $0.5 \mathrm{mM} \mathrm{MgCl}, 10 \mathrm{mM} \mathrm{KCl}, 0.025 \%$ Tween-20, $0.063 \mathrm{mg} \mathrm{ml}^{-1}$ tRNA and $2 \mathrm{mM}$ dithiothreitol. Compounds were pre-incubated in reaction buffer with IRE1 $\alpha$ proteins for $1 \mathrm{~h}$ at room temperature. On addition of RNA substrate (diluted in $10 \mathrm{mM}$ Tris pH 7.0 and $0.1 \mathrm{mM}$ EDTA), cleavage reactions were monitored in real time by fluorescence intensity $\left(\lambda_{\text {excited }}=651 \mathrm{~nm}, \lambda_{\text {emission }}=672 \mathrm{~nm}\right)$ at 2 -min intervals using a Molecular Dimensions Analyst HT microplate reader. Gel-based RNA cleavage assays were performed in the same reaction buffer as above with the addition of $0.09 \mathrm{mg} \mathrm{ml}^{-1}$ bovine serum albumin. A single hairpin RNA substrate (5'-CAUGUCCGCAGCGC AUG-3') labelled with fluorescein on the $5^{\prime}$ terminus was used at a concentration of $45 \mathrm{nM}$. Reactions were pre-incubated with inhibitor compound for $1 \mathrm{~h}$ at room temperature, and then on addition of RNA substrate for $10-45 \mathrm{~min}$ at $37^{\circ} \mathrm{C}$. Reactions were quenched by addition of $2 \times$ RNA loading buffer (90\% (v/v) formamide, $25 \mathrm{mM}$ EDTA) and samples were analysed using $20 \%$ Urea-TBE (Tris/ Borate/EDTA) PAGE and imaged via a GE Healthcare Typhoon Variable Mode Imager. Images were quantified using ImageQuant5 software.

The gel-based RNase cleavage assay shown in Fig. $4 \mathrm{~d}$ was performed in a reaction buffer containing $1 \mathrm{M}$ Hepes $\mathrm{pH} 7.0,100 \mathrm{mM}$ ADP, $100 \mathrm{mM} \mathrm{MgCl}_{2}$ and $100 \mathrm{mM}$ TCEP, with $100 \mu \mathrm{M}$ murine IRE $1 \alpha$ and $60 \mu \mathrm{M}$ of an unlabelled dual-hairpin RNA substrate encompassing human XBP1 nucleotide positions $426-490$ generated by in vitro transcription reactions. Cleavage reactions were pre-incubated with compound for $30 \mathrm{~min}$ on ice and after addition of RNA substrate further for $45 \mathrm{~min}$ at room temperature. Reactions were quenched by the addition of $2 \times$ RNA loading buffer (90\% formamide, $25 \mathrm{mM}$ EDTA, $0.02 \%$ xylene cyanol and $0.02 \%$ bromophenol blue) and samples were analysed using $20 \%$ Urea-TBE PAGE, stained with RedSafe dye and imaged via a GE Healthcare Typhoon Variable Mode Imager.

Direct HAA inhibitor-binding analyses. Microscale thermophoresis was performed with $500 \mathrm{nM}$ murine IRE1 $\alpha$ and $0.05 \%$ Pluronic in non-coated standard capillaries. The reactions were performed in a buffer containing $25 \mathrm{mM}$ Hepes $\mathrm{pH} 7.0,0.5 \mathrm{M} \mathrm{NaCl}$ and $2 \mathrm{mM}$ TCEP. MKC9989, OICR464 and OICR573 inhibitor-binding reactions employed final DMSO concentrations of 1,5 and $2 \%$, respectively. All measurements were performed at $20 \%$ microscale thermophoresis power and 20\% light-emitting diode power using the Monolith NT.LabelFree instrument (NanoTemper Technologies).

Chemical synthesis. MKC9989, OICR573, OICR464 and the napthalene analogue series shown in Fig. 5 were synthesized using methods described in WO 2011/ 127070 A2 (MKC9989) and WO2008/154484 A1 (OICR573 and OICR464) with commercially available chemical reagents. (7-Hydroxy-6-methoxy-3-(2-(2-methoxyethoxy)ethyl)-4-methyl-2-oxo-2H-chromene-8-carbaldehyde) was synthesized as shown in Scheme 1. 2-Hydroxy-3-methoxy-5-(4-methyl-3,4-dihydro-2H-benzo[b][1,4] oxazin-7-yl)benzaldehyde and 4-hydroxy-5-methoxy-4'-morpholino$\left[1,1^{\prime}\right.$-biphenyl] 3 -carbaldehyde were synthesized as shown in Scheme 2 and 3, respectively.

Toluene-4-sulphonic acid 2-(2-methoxy-ethoxy)-ethyl ester. A mixture of $125 \mathrm{ml}$ aqueous $\mathrm{NaOH}(2.38 \mathrm{~g}, 0.0595 \mathrm{~mol})$ solution and $200 \mathrm{ml}$ tetrahydrofuran (THF) 2-(2-methoxy-ethoxy)-ethanol $(5 \mathrm{~g}, 0.042 \mathrm{~mol})$ was cooled to $0{ }^{\circ} \mathrm{C}$ in a round bottom flask. A $200 \mathrm{ml}$ THF solution of $\mathrm{TsCl}(7.38 \mathrm{~g}, 0.0388 \mathrm{~mol})$ was added

$$
\text { HO } \sim \mathrm{HO}_{\mathrm{O}} \frac{\mathrm{TsCl}, \mathrm{NaOH}}{\mathrm{H}_{2} \mathrm{O} / \mathrm{THF}, \mathrm{RT}} \longrightarrow \mathrm{TsO} \sim \mathrm{O} \sim \mathrm{O}^{-}
$$
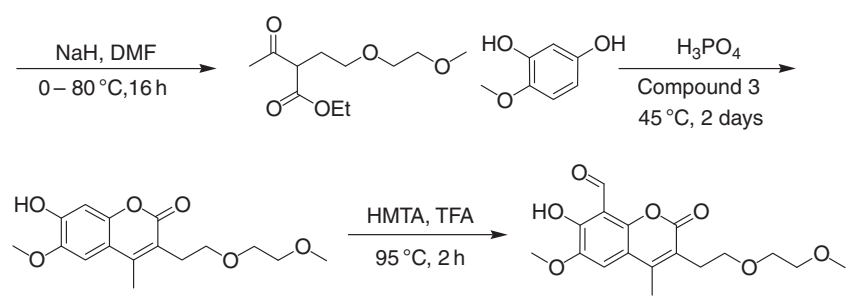

Scheme 1 I Synthesis of MKC9989 (7-hydroxy-6-methoxy-3-(2-(2-methoxye thoxy)ethyl)-4-methyl-2-oxo-2H-chromene-8-carbaldehyde) 

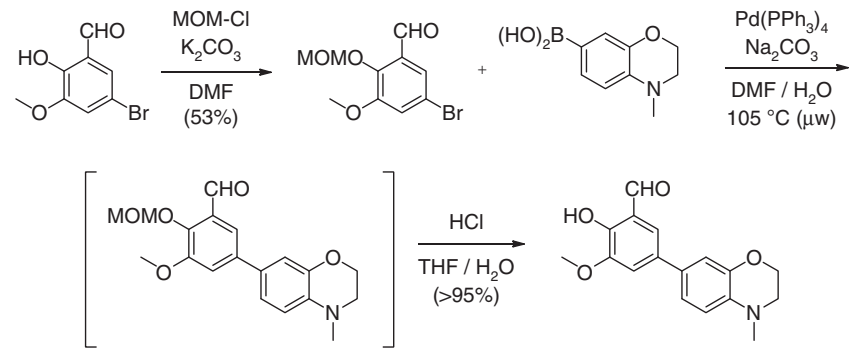

Scheme 2 I Synthesis of OICR464 (2-hydroxy-3-methoxy-5-(4-methyl-3,4dihydro-2H-benzo[b][1,4]oxazin-7-yl)benzaldehyde).
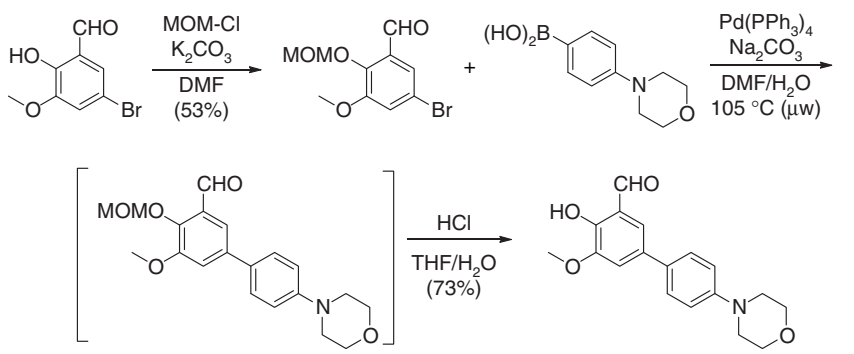

Scheme 3 I Synthesis of OICR573 (4-hydroxy-5-methoxy-4'-morpholino-[1,1'biphenyl]-3-carbaldehyde).

dropwise to the flask with stirring while keeping the inner temperature below $5^{\circ} \mathrm{C}$. After the addition, the reaction mixture was stirred at $0^{\circ} \mathrm{C}-5^{\circ} \mathrm{C}$ for additional $2 \mathrm{~h}$. The reaction mixture was poured into a flask with $500 \mathrm{ml}$ ice water. The resulting mixture was extracted with $150 \mathrm{ml}$ DCM trice. The combined dichloromethane (DCM) solution was washed with water and brine, dried over $\mathrm{Na}_{2} \mathrm{SO}_{4}$ and concentrated to afford a light yellow needle-like solid as the desired product $(9.50 \mathrm{~g}$, yield: $89 \%) .{ }^{1} \mathrm{H}$ NMR $\left(400 \mathrm{MHz}, \mathrm{CDCl}_{3}\right): \delta 7.79(\mathrm{~d}, J=8.4 \mathrm{~Hz}, 2 \mathrm{H}, \mathrm{ArH}), 7.33$ $(\mathrm{d}, J=8.4 \mathrm{~Hz}, 2 \mathrm{H}, \mathrm{ArH}), 4.16\left(\mathrm{t}, J=4.8 \mathrm{~Hz}, 2 \mathrm{H}, \mathrm{CH}_{2}\right), 3.68\left(\mathrm{t}, J=4.8 \mathrm{~Hz}, 2 \mathrm{H}, \mathrm{CH}_{2}\right)$, 3.58-3.56 (m, $\left.2 \mathrm{H}, \mathrm{CH}_{2}\right), 3.48-3.47\left(\mathrm{~m}, 2 \mathrm{H}, \mathrm{CH}_{2}\right), 3.34\left(\mathrm{~s}, 3 \mathrm{H}, \mathrm{OCH}_{3}\right), 2.44$ $\left(\mathrm{s}, 3 \mathrm{H}, \mathrm{ArCH}_{3}\right)$

2-[2-(2-Methoxy-ethoxy)-ethyl]-3-oxo-butyric acid ethyl ester. To a $25 \mathrm{ml}$ dimethylformamide (DMF) suspension of $\mathrm{NaH}(0.992 \mathrm{~g}, 0.0248 \mathrm{~mol})$ in a round bottom flask was added dropwise a $550 \mathrm{ml}$ DME solution of acetyl ethylacetate $(3.07 \mathrm{~g}, 0.0236 \mathrm{~mol})$ at $0{ }^{\circ} \mathrm{C}$. After the addition, the resulting mixture was stirred at $20^{\circ} \mathrm{C}$ for $30 \mathrm{~min}$. To the flask at $20^{\circ} \mathrm{C}$ was added successively a solution of toluene-4-sulphonic acid 2-(2-methoxy-ethoxy)-ethyl ester $(6.79 \mathrm{~g}, 0.0247 \mathrm{mmol})$ in $100 \mathrm{ml} \mathrm{DME}$ and NaI $(3.72 \mathrm{~g}, 0.0248 \mathrm{~mol})$ powder. The resulting mixture was stirred at $20^{\circ} \mathrm{C}$ for $2 \mathrm{~h}$ untill seeing some precipitate formed. The mixture was then heated to $80^{\circ} \mathrm{C}$ overnight under $\mathrm{N}_{2}$. Progress of the reaction was monitored by liquid chromatography mass spectrometry (LCMS) analysis. The reaction was completed in $16 \mathrm{~h}$. After a filtration and removing the precipitate, the filtrate was collected and concentrated to a minimum volume. It was then diluted with $\mathrm{H}_{2} \mathrm{O}$ and acidified with $2 \mathrm{~N} \mathrm{HCl}$ to $\mathrm{pH}=3$, extracted with $100 \mathrm{ml}$ DCM trice. The combined DCM solution was concentrated to a crude product that was purified by silica gel column (PE: EA =6:1) chromatography affording a light yellow oil (1.8 g, 32\% yield) as the product 2-[2-(2-methoxy-ethoxy)-ethyl]-3oxo-butyric acid ethyl ester. ${ }^{1} \mathrm{H}$ NMR $\left(400 \mathrm{MHz}, \mathrm{CDCl}_{3}\right): \delta 4.19-4.16(\mathrm{~m}, 2 \mathrm{H}$, $\left.\mathrm{CH}_{2}\right), 4.12-4.10(\mathrm{~m}, 1 \mathrm{H}, \mathrm{CH}), 3.66(\mathrm{~m}, 1 \mathrm{H}, \mathrm{CH}), 3.52-3.48\left(\mathrm{~m}, 6 \mathrm{H}, 3 \mathrm{CH}_{2}\right), 3.36$ (s, $\left.3 \mathrm{H}, \mathrm{OCH}_{3}\right), 2.25\left(\mathrm{~s}, 3 \mathrm{H}, \mathrm{COCH}_{3}\right), 2.17-2.11\left(\mathrm{~m}, 2 \mathrm{H}, \mathrm{CH}_{2}\right), 1.49(\mathrm{t}, J=7.2 \mathrm{~Hz}$, $\left.3 \mathrm{H}, \mathrm{CH}_{3}\right)$.

7-Hydroxy-6-methoxy-3-[2-(2-methoxy-ethoxy)-ethyl]-4-methyl-chromen-2-one. 2[2-(2-Methoxy-ethoxy)-ethyl]-3-oxo-butyric acid ethyl ester $(2.25 \mathrm{~g}, 0.0097 \mathrm{~mol})$ and 2-hydroxyl-3-methoxyl-phenol $(1.30 \mathrm{~g}, 0.0093 \mathrm{~mol})$ were mixed with $200 \mathrm{ml} \mathrm{H}_{3} \mathrm{PO}_{4}$ in a round bottom flask. The reaction mixture was stirred at $45^{\circ} \mathrm{C}$ for 2 days. After the reaction was completed, the mixture was diluted with EA $(100 \mathrm{ml})$ and poured into a flask with 11 ice water. The resulting mixture was stirred for $15 \mathrm{~min}$. After a filtration, the solid obtained was washed with cold saturated $\mathrm{NaHCO}_{3}$, brine and $\mathrm{H}_{2} \mathrm{O}$ successively. The solid was dried with toluene azeotropy distillation affording a light yellow solid as the product ( $1.25 \mathrm{~g}, 41 \%$ yield). ${ }^{1} \mathrm{H}$ NMR (400 MHz, DMSO-d6): $\delta 7.14(\mathrm{~s}, 1 \mathrm{H}$, $\operatorname{ArH}), 6.74(\mathrm{~s}, 1 \mathrm{H}, \mathrm{ArH}), 3.85\left(\mathrm{~s}, 3 \mathrm{H}, \mathrm{CH}_{3}\right), 3.49-3.47\left(\mathrm{~m}, 4 \mathrm{H}, 2 \mathrm{CH}_{2}\right)$, $3.41-3.33\left(\mathrm{~m}, 2 \mathrm{H}, \mathrm{CH}_{2}\right), 3.20\left(\mathrm{~s}, 3 \mathrm{H}, \mathrm{CH}_{3}\right), 2.78\left(\mathrm{t}, J=7.2 \mathrm{~Hz}, 2 \mathrm{H}, \mathrm{CH}_{2}\right), 2.40$ $\left(\mathrm{s}, 3 \mathrm{H}, \mathrm{CH}_{3}\right)$.
MKC9989 (7-hydroxy-6-methoxy-3-(2-(2-methoxyethoxy)ethyl)-4-methyl-2-oxo-2Hchromene-8-carbaldehyde). 7-Hydroxy-6-methoxy-3-[2-(2-methoxy-ethoxy)ethyl]-4-methyl-chromen-2-one $(2.0 \mathrm{~g}, 0.0064 \mathrm{~mol})$ and hexamethylenetetramine (HTMA) (3.65 g, $0.026 \mathrm{~mol}$ ) were dissolved in $85 \mathrm{ml}$ trifluoroacetic acid (TFA) in a round bottom flask. The reaction mixture was heated to $95^{\circ} \mathrm{C}$ for $2 \mathrm{~h}$.

Progress. After the reaction was completed, the reaction mixture was concentrated. The residue was diluted with $\mathrm{H}_{2} \mathrm{O}$, extracted with $100 \mathrm{ml}$ DCM trice. The combined DCM solution was washed with cold saturated $\mathrm{NaHCO}_{3}$, brine, dried over $\mathrm{Na}_{2} \mathrm{SO}_{4}$ and concentrated. The remaining residue was purified with a silica gel column (DCM: $\mathrm{MeOH}=100: 1$ ) chromatography affording $1.3 \mathrm{~g}$ of desired crude product. The product was further purified by recrystallization from EA, affording 7-hydroxy-6-methoxy-3-(2-(2-methoxyethoxy)ethyl)-4-methyl-2-oxo-2Hchromene-8-carbaldehyde $(0.8 \mathrm{~g}, 37 \%$ yield $)$ as a yellow solid. ${ }^{1} \mathrm{H}$ NMR $(400 \mathrm{MHz}$, $\mathrm{CDCl}_{3}$ ): $\delta$ p.p.m. 12.46 (s, 1H, OH), $10.66(\mathrm{~s}, 1 \mathrm{H}, \mathrm{CHO}), 7.30$ (s, 1H, ArH), 4.01 (s, $\left.3 \mathrm{H}, \mathrm{ArOCH}_{3}\right), 3.72\left(\mathrm{t}, J=6.8 \mathrm{~Hz}, 2 \mathrm{H}, \mathrm{CH}_{2}\right), 3.65-3.64\left(\mathrm{~m}, 2 \mathrm{H}, \mathrm{CH}_{2}\right), 3.56-3.55(\mathrm{~m}$, $\left.2 \mathrm{H}, \mathrm{CH}_{2}\right), 3.40\left(\mathrm{~s}, 3 \mathrm{H}, \mathrm{OCH}_{3}\right), 3.02\left(\mathrm{t}, J=6.8 \mathrm{~Hz}, 2 \mathrm{H}, \mathrm{CH}_{2}\right), 2.49\left(\mathrm{~s}, 3 \mathrm{H}, \mathrm{CH}_{3}\right)$; LCMS $[\mathrm{M}+\mathrm{H}]^{+}=337.2 ;{ }^{13} \mathrm{C}$ NMR (126 MHz, DMSO-d6) $\delta$ p.p.m. 192.40, $160.38,154.10,149.15,147.63,144.96,120.01,113.59,111.65,09 / 42,71.79,69.91$, 68.94, 58.56, 56.99, 28.15, 15.86 .

5-Bromo-3-methoxy-2-(methoxymethoxy)benzaldehyde. $\mathrm{MOM}-\mathrm{Cl}(1.4 \mathrm{ml}$, $19 \mathrm{mmol}$ ) was added dropwise to a stirring mixture of 5-bromo-2-hydroxy-3methoxybenzaldehyde $(4.0 \mathrm{~g}, 17 \mathrm{mmol})$ and $\mathrm{K}_{2} \mathrm{CO}_{3}(4.8 \mathrm{~g}, 35 \mathrm{mmol})$ in DMF $(100 \mathrm{ml})$ at $0^{\circ} \mathrm{C}$. The reaction was allowed to warm to room temperature with stirring overnight. The reaction was quenched with a saturated $\mathrm{NH}_{4} \mathrm{Cl}$ solution and the product was extracted into EtOAc. The combined organic extracts were dried and concentrated to dryness in vaccuo. The residue was purified by flash chromatography (EtOAc/hexanes) to afford the title compound $(2.5 \mathrm{~g}, 53 \%$ yield) as a solid. LCMS $[\mathrm{M}+\mathrm{H}]+=275.1$.

OICR464 (2-hydroxy-3-methoxy-5-(4-methyl-3,4-dihydro-2H-benzo[b][1,4] oxazin-7-yl)benzaldehyde). A mixture of 5-bromo-3-methoxy-2-

(methoxymethoxy)benzaldehyde $(0.100 \mathrm{~g}, 0.36 \mathrm{mmol})$, (4-methyl-3,4-dihydro- $2 \mathrm{H}-$ benzo[b][1,4]oxazin-7-yl)boronic acid $(0.074 \mathrm{~g}, 0.38 \mathrm{mmol}), \mathrm{Pd}\left(\mathrm{PPh}_{3}\right)_{4}(0.013 \mathrm{~g}$, $0.011 \mathrm{mmol})$ and $\mathrm{Na}_{2} \mathrm{CO}_{3}(0.116 \mathrm{~g}, 1.1 \mathrm{mmol})$ in DMF $(2 \mathrm{ml})$ and $\mathrm{H}_{2} \mathrm{O}(2 \mathrm{ml})$ was irradiated in the microwave to a temperature of $105^{\circ} \mathrm{C}$ for $20 \mathrm{~min}$. The reaction was partitioned between EtOAc and $\mathrm{H}_{2} \mathrm{O}$ and the layers were separated. The organic layer was washed with $\mathrm{H}_{2} \mathrm{O}$, dried over magnesium sulphate and concentrated to dryness. The residue was dissolved in THF $(10 \mathrm{ml})$ and treated with $3 \mathrm{M} \mathrm{HCl}_{\text {(Aq.) }}(10 \mathrm{ml})$. THF was removed and the resultant acidic media was extracted with DCM. The organics were concentrated to dryness and the residue was purified by flash chromatography $(2-8 \% \mathrm{MeOH} / \mathrm{DCM})$ to afford the title compound $\left(0.105 \mathrm{~g}, 96 \%\right.$ yield) as a yellow solid. ${ }^{1} \mathrm{H}$ NMR $(500 \mathrm{MHz}, \mathrm{DMSO}-\mathrm{d} 6) \delta$ p.p.m.: 10.28 (s, 1H), 7.42-7.36 (m, 2H), 7.10 (dd, $J=2.0,8.3 \mathrm{~Hz}, 1 \mathrm{H}), 7.00$ $(\mathrm{d}, J=1.8 \mathrm{~Hz}, 1 \mathrm{H}), 6.76(\mathrm{~d}, J=8.4 \mathrm{~Hz}, 1 \mathrm{H}), 4.30-4.23(\mathrm{~m}, 2 \mathrm{H}), 3.93(\mathrm{~s}, 3 \mathrm{H})$, $3.27-3.24(\mathrm{~m}, 2 \mathrm{H}), 2.86(\mathrm{~s}, 3 \mathrm{H})$; LCMS $[\mathrm{M}+\mathrm{H}]+=300.2 ;{ }^{13} \mathrm{C}$ NMR $(126 \mathrm{MHz}$, DMSO-d6) $\delta$ p.p.m.: 192.76, 150.16, 149.24, 144.62, 136.54, 131.91, 129.24, 122.88, $119.53,117.23,115.76,113.58,113.26,64.99,56.68,48.90,38.76$.

5-Bromo-3-methoxy-2-(methoxymethoxy)benzaldehyde. MOM-Cl (1.4 mL, $19 \mathrm{mmol}$ ) was added dropwise to a stirring mixture of 5-bromo-2-hydroxy-3methoxybenzaldehyde $(4.0 \mathrm{~g}, 17 \mathrm{mmol})$ and $\mathrm{K}_{2} \mathrm{CO}_{3}(4.8 \mathrm{~g}, 35 \mathrm{mmol})$ in DMF $(100 \mathrm{~mL})$ at $0{ }^{\circ} \mathrm{C}$. The reaction was allowed to warm to room temperature with stirring overnight. The reaction was quenched with a saturated $\mathrm{NH}_{4} \mathrm{Cl}$ solution and the product was extracted into EtOAc. The combined organic extracts were dried and concentrated to dryness in vaccuo. The residue was purified by flash chromatography (EtOAc/hexanes) to afford the title compound ( $2.5 \mathrm{~g}, 53 \%$ yield) as a solid. LCMS $[\mathrm{M}+\mathrm{H}]+=275.1$.

OICR573 (4-hydroxy-5-methoxy-4'-morpholino-[1,1'-biphenyl]-3-carbaldehyde). A mixture of 5-bromo-3-methoxy-2-(methoxymethoxy)benzaldehyde (0.104 g, $0.38 \mathrm{mmol})$, (4-methyl-3,4-dihydro-2H-benzo[b][1,4] oxazin-7-yl)boronic acid $(0.114 \mathrm{~g}, 0.55 \mathrm{mmol}), \mathrm{Pd}\left(\mathrm{PPh}_{3}\right)_{4}(0.022 \mathrm{~g}, 0.019 \mathrm{mmol})$ and $\mathrm{Na}_{2} \mathrm{CO}_{3}(0.190 \mathrm{~g}$, $1.5 \mathrm{mmol})$ in DMF $(2 \mathrm{ml})$ and $\mathrm{H}_{2} \mathrm{O}(2 \mathrm{ml})$ was irradiated in the microwave to a temperature of $110^{\circ} \mathrm{C}$ for $30 \mathrm{~min}$. The reaction was partitioned between EtOAc and $\mathrm{H}_{2} \mathrm{O}$ and the layers were separated. The organic layer was washed with $\mathrm{H}_{2} \mathrm{O}$, dried over magnesium sulphate and concentrated to dryness. The residue was dissolved in THF $(10 \mathrm{ml})$ and treated with $3 \mathrm{M} \mathrm{HCl}_{(\mathrm{Aq.})}(10 \mathrm{ml})$. THF was removed and the resultant acidic media were extracted with DCM. The organics were concentrated to dryness and the residue was purified by flash chromatography (10-70\% Hexane/EtOAc) to afford the title compound $(0.087 \mathrm{~g}, 73 \%$ yield) as a yellow solid. ${ }^{1} \mathrm{H}$ NMR (500 MHz, DMSO-d6) $\delta$ p.p.m. 10.32 (s, 1H), 10.35-10.15 (bs, $1 \mathrm{H}), 7.56(\mathrm{~d}, J=8.7 \mathrm{~Hz}, 2 \mathrm{H}), 7.46(\mathrm{~s}, 2 \mathrm{H}), 7.02(\mathrm{~d}, J=8.7,2 \mathrm{H}), 3.95(\mathrm{~s}, 3 \mathrm{H})$, 3.85-3.70 (m, 4H), 3.25-3.10 (m, 4H); ${ }^{13} \mathrm{C}$ NMR (126 MHz, DMSO-d6) $\delta$ p.p.m. $192.54,150.73,150.06,149.23,131.91,130.35,127.31(2 \mathrm{C}), 122.98,117.27,115.86$, $115.74(2 \mathrm{C}), 66.52(2 \mathrm{C}), 56.70,48.74(2 \mathrm{C})$; LCMS $[\mathrm{M}+\mathrm{H}]+=314.1$.

MKC3946 (2-hydroxy-6-[5-(4-methyl-piperazine-1-carbonyl)-thiophen-2-yl]naphthalene-1-carbaldehyde) was synthesized as shown in Scheme 4. 

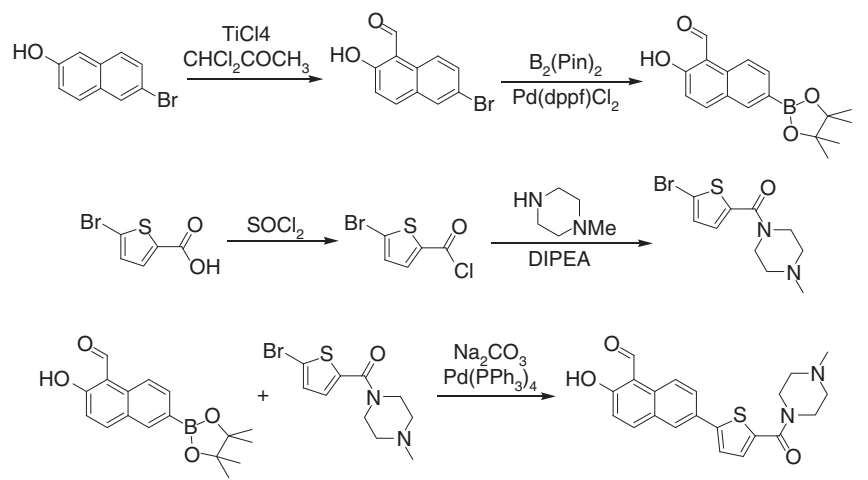

Scheme 4 I Synthesis of MKC3946 ( 2-Hydroxy-6-[5-(4-methyl-piperazine-1carbonyl)-thiophen-2-yl]-naphthalene-1-carbaldehyde).

6-Bromo-2-hydroxy-naphthalene-1-carbaldehyde. A solution of titanium tetrachloride $(16.5 \mathrm{ml}, 28.5 \mathrm{~g}, 150 \mathrm{mM})$ in methylene chloride $(300 \mathrm{ml})$ was stirred under ice cooling in a 21 three-necked flask, equipped with a thermometer, a dropping funnel and a gas outlet with a paraffin oil-filled bubbler. To the flask, dichloromethyl methyl ether $(24.4 \mathrm{ml}, 31 \mathrm{~g}, 270 \mathrm{mM})$ was added dropwise for $10 \mathrm{~min}$ resulting in a yellow solution. Then, a solution of 6-bromo-2-naphthol $(20 \mathrm{~g}, 89.7 \mathrm{mM})$ in methylene chloride $(300 \mathrm{ml})$ was added dropwise for $30 \mathrm{~min}$ whereupon the color of the mixture turned deep brownish-red and only a slight $\left(3-4{ }^{\circ} \mathrm{C}\right)$ increase in the internal temperature was observed. Thereafter, the cooling batch was removed and the mixture was stirred at ambient temperature overnight. The next day, $1,000 \mathrm{ml}$ of $1 \mathrm{~N}$ hydrochloric acid was added under ice cooling whereupon, during the first $10-15 \mathrm{~min}$ of the addition, extensive gas evolution was observed. After the addition was complete and the color of the mixture turned yellow, a small amount ( $0.78 \mathrm{~g}$ after drying) of a brick-red insoluble substance was filtered off. The aqueous layer was separated and extracted with methylene chloride $(2 \times 100 \mathrm{ml})$. The combined organic solutions were washed with $1 \mathrm{~N}$ hydrochloric acid $(100 \mathrm{ml})$, then with brine $(5 \times 100 \mathrm{ml})$, dried over anhydrous $\mathrm{MgSO}_{4}$ and evaporated to dryness. The brownish-yellow residue was triturated with diethyl ether; the yellow crystalline product was filtered off, washed with diethyl ether and dried over solid $\mathrm{NaOH}$ under reduced pressure as the desired product $(16.95 \mathrm{~g}$, $75.3 \%)$, m.p. $142-146^{\circ} \mathrm{C},{ }^{1} \mathrm{H}$ NMR ( $400 \mathrm{MHz}$, DMSO-d6) $\delta$ ppm: $11.90(\mathrm{~s}, 1 \mathrm{H})$, $10.76(\mathrm{~s}, 1 \mathrm{H}), 8.92(\mathrm{~d}, J=9.3 \mathrm{~Hz}, 1 \mathrm{H}), 8.16(\mathrm{~d}, J=2.0 \mathrm{~Hz}, 1 \mathrm{H}), 8.10(\mathrm{~d}, J=9.3 \mathrm{~Hz}$ $1 \mathrm{H}), 7.72(\mathrm{dd}, J=9.0,2.3 \mathrm{~Hz}, 1 \mathrm{H}), 7.30(\mathrm{~d}, J=9.0 \mathrm{~Hz}, 1 \mathrm{H})$. This product is used in the next step without any further purification.

\section{2-Hydroxy-6-(4,4,5,5-tetramethyl-[1,3,2]dioxaborolan-2-yl)-naphthalene-1-} carbaldehyde. A mixture of 6-bromo-2-hydroxy-naphthalene-1-carbaldehyde $(10.0 \mathrm{~g}, 39.8 \mathrm{mM}), 1,4$-dioxane $(160 \mathrm{ml}$, distilled freshly from sodium metal, under nitrogen), bis(pinacolato)diborone $(11.1 \mathrm{~g}, 43.8 \mathrm{mM})$, powdered potassium acetate $(11.8 \mathrm{~g}, 120 \mathrm{mM})$ and palladium[ $1,1^{\prime}$-bis(diphenylphosphino)ferrocene]dichloride methylene chloride complex $(3.9 \mathrm{~g}, 4.8 \mathrm{mM})$ was stirred at $80-85^{\circ} \mathrm{C}$ under a slow stream of nitrogen for $4 \mathrm{~h}$. After cooling, the insolubles were filtered off and washed with 1,4-dioxane. The solvent was evaporated and the dark brown residue was purified by chromatography over silica $(200 \mathrm{~g})$ using methylene chloride as eluent to yield the product $(10.4 \mathrm{~g}, 87.6 \%)$ a yellow powder in $86 \%$ HPLC purity, m.p. 115$118^{\circ} \mathrm{C}$.The product can be further purified by recrystallization from sixfold $(\mathrm{v} / \mathrm{w})$ diisopropyl ether with final yield as $54 \%$. ${ }^{1} \mathrm{H}$ NMR $(400 \mathrm{MHz}, \mathrm{CDCl} 3) \delta$ p.p.m.: $13.23(\mathrm{~s}, 1 \mathrm{H}), 10.82(\mathrm{~s}, 1 \mathrm{H}), 8.33(\mathrm{~d}, J=8.8 \mathrm{~Hz}, 1 \mathrm{H}), 8.29(\mathrm{~s}, 1 \mathrm{H}), 8.02(\mathrm{~d}, J=9.0 \mathrm{~Hz}$, $1 \mathrm{H}), 7.98(\mathrm{dd}, J=8.5,1.3 \mathrm{~Hz}, 1 \mathrm{H}), 7.13(\mathrm{~d}, J=9.0 \mathrm{~Hz}, 1 \mathrm{H}), 1.39(\mathrm{~s}, 12 \mathrm{H})$.

5-Bromo-thiophene-2-carbonyl chloride. 5-Bromo-thiophene-2-carboxylic acid $(9.09 \mathrm{~g}$ was dissolved in $100 \mathrm{ml}$ thionyl chloride and the solution was refluxed for 1 h. After completion of the reaction, the excess of thionyl chloride was removed under reduced pressure. $(9.60 \mathrm{~g})$ Solid residue was obtained and used in the next step without further purification.

(5-Bromo-thiophen-2-yl)-(4-methyl-piperazin-1-yl)-methanone. 1-Me-piperazine $(4.27 \mathrm{~g})$ and $5.54 \mathrm{~g}$ of DIPEA were dissolved in $80 \mathrm{ml}$ of dry methylene chloride and the resulting solution was added dropwise at $0^{\circ} \mathrm{C}$ to a solution of $9.60 \mathrm{~g}$ of 5 bromo-thiophene-2-carbonyl chloride in dry methylene chloride. The stirred solution was allowed to warm to room temperature and was washed with water. The organic phase was separated, dried and evaporated. The obtained $12.08 \mathrm{~g}$ of light brown oil was allowed to stand in the refrigerator overnight whereupon it solidified to a yellow-brownish solid (yield $=98 \%$ ). The product was used directly for the next step without further purification.

2-Hydroxy-6-[5-(4-methyl-piperazine-1-carbonyl)-thiophen-2-yl]-naphthalene-1carbaldehyde. 2-Hydroxy-6-(4,4,5,5-tetramethyl-[1,3,2]dioxaborolan-2-yl)naphthalene-1-carbaldehyde $(5.50 \mathrm{~g}, 18.4 \mu \mathrm{mol})$, (5-bromo-thiophen-2-yl)- (4-methyl-piperazin-1-yl)-methanone $(5.60 \mathrm{~g}, 19.3 \mu \mathrm{mol})$ and sodium carbonate $(11.70 \mathrm{~g})$ were dissolved in a mixture of $500 \mathrm{ml}$ dimethylformamide (DMF) and $500 \mathrm{ml}$ water. To this mixture was added $644 \mathrm{mg}$ tetrakis(triphenylphosphino)palladium. The reaction mixture was heated to $100{ }^{\circ} \mathrm{C}$ under nitrogen atmosphere. The progress was monitored by TLC. After $1 \mathrm{~h}$, the reaction mixture was evaporated and the solid residues were partitioned between $400 \mathrm{ml}$ water and $300 \mathrm{ml}$ chloroform. The aqueous phase was extracted with additional $300 \mathrm{ml}$ chloroform. The combined organic layer was dried over sodium sulfate. Evaporation of the solvent resulted in $7.00 \mathrm{~g}$ of a reddish powder, which was purified by flash column chromatography with chloroform as eluent. The isolated $6.88 \mathrm{~g}$ of crude material were suspended in ethanol and cooled to $0^{\circ} \mathrm{C}$. Saturated solution of $\mathrm{HCl}(70 \mathrm{ml})$ in ethyl acetate was added to the stirred suspension and was stirred overnight at room temperature. An additional portion of $\mathrm{HCl} / \mathrm{EtOAc}$ was then added, the suspension was cooled again to $0^{\circ} \mathrm{C}$. The product was filtered off, washed with EtOAc and diethyl ether to yield a yellow powder $(5.67 \mathrm{~g}, 74 \%)$ as the desired product. ${ }^{1} \mathrm{H}$ NMR $\left(400 \mathrm{MHz}, \mathrm{CDCl}_{3}\right) \delta$ p.p.m.: 13.13 (br. s, $\left.1 \mathrm{H}\right), 10.82(\mathrm{~s}, 1 \mathrm{H}), 8.37(\mathrm{~d}, J=9.0 \mathrm{~Hz}$, $1 \mathrm{H}), 7.97-8.05(\mathrm{~m}, 2 \mathrm{H}), 7.86(\mathrm{dd}, J=8.8,2.0 \mathrm{~Hz}, 1 \mathrm{H}), 7.30-7.35(\mathrm{~m}, 2 \mathrm{H}), 7.19$ (d, $J=9.0 \mathrm{~Hz}, 1 \mathrm{H}), 3.78-3.88(\mathrm{~m}, 4 \mathrm{H}), 2.45-2.55(\mathrm{~m}, 4 \mathrm{H}), 2.35$ (s, 3H). LCMS $[\mathrm{M}+\mathrm{H}]^{+}=381.1$.

MKC3987 (7-bromo-2-hydroxy-naphthalene-1-carbaldehyde). This compound was synthesized in a same manner as 6-bromo-2-hydroxy-naphthalene-1-carbaldehyde as shown in Scheme 4 using 7-bromo-naphthalen-2-ol as the starting material. ${ }^{1} \mathrm{H}$ NMR (400 MHz, $\left.\mathrm{CDCl}_{3}\right) \delta$ p.p.m.: $13.17(\mathrm{~s}, 1 \mathrm{H}, \mathrm{OH}), 10.73(\mathrm{~s}, 1 \mathrm{H}, \mathrm{CHO}), 8.49(\mathrm{~s}$, $1 \mathrm{H}, \mathrm{ArH}), 7.93(\mathrm{~d}, 1 \mathrm{H}, J=8.8 \mathrm{~Hz}, \mathrm{ArH}), 7.66(\mathrm{~d}, 1 \mathrm{H}, J=8.8 \mathrm{~Hz}, \mathrm{ArH}), 7.53(\mathrm{dd}$, $1 \mathrm{H}, J=0.8,8.8 \mathrm{~Hz}, \mathrm{ArH}), 7.15(\mathrm{~d}, J=8.8 \mathrm{~Hz}, \operatorname{ArH})$; LCMS $[\mathrm{M}+\mathrm{H}]^{+}$m/e: 251 (100\%), $253(100 \%)$.

MKC4027 (2-hydroxy-7-[4-(4-methyl-piperazine-1-carbonyl)-phenyl]naphthalene-1-carbaldehyde). This compound was synthesized in a similar manner as shown in Scheme 4 using 7-bromo-2-hydroxy-naphthalene-1-carbaldehyde to make the Suzuki coupling boronic ester 2-hydroxy-7-(4,4,5,5-tetramethyl$[1,3,2]$ dioxaborolan-2-yl) -naphthalene-1-carbaldehyde, which was then coupled with (4-bromo-phenyl)-(4-methyl-piperazin-1-yl)-methanone to form the target compound. ${ }^{1} \mathrm{H}$ NMR $\left(400 \mathrm{MHz}, \mathrm{CDCl}_{3}\right) \delta$ p.p.m.: $13.2(\mathrm{~s}, 1 \mathrm{H}, \mathrm{OH}), 10.90(\mathrm{~s}, 1 \mathrm{H}$, CHO), $8.52(\mathrm{~d}, 1 \mathrm{H}, \mathrm{J}=0.8 \mathrm{~Hz}, \mathrm{ArH}), 8.01(\mathrm{~d}, 1 \mathrm{H}, \mathrm{J}=8.8 \mathrm{~Hz}, \mathrm{ArH}), 7.88(\mathrm{~d}, 1 \mathrm{H}$, $J=8.8 \mathrm{~Hz}, \mathrm{ArH}), 7.75(\mathrm{ddd}, 2 \mathrm{H}, J=0.8,0.8,8.4 \mathrm{~Hz}, \mathrm{ArH}), 7.66(\mathrm{dd}, 1 \mathrm{H}, J=0.8 \mathrm{~Hz}$, ArH), 7.55 (ddd, $2 \mathrm{H}, J=0.8,0.8,8.4 \mathrm{~Hz}, \mathrm{ArH}), 7.17$ (d, $1 \mathrm{H}, J=8.8 \mathrm{~Hz}, \mathrm{ArH}), 3.7$ (br, $\left.4 \mathrm{H},-\mathrm{CH}_{2}\right), 2.5\left(\mathrm{br}, 4 \mathrm{H},-\mathrm{CH}_{2}\right), 2.35\left(\mathrm{~s}, 3 \mathrm{H},-\mathrm{CH}_{3}\right)$; LCMS $[\mathrm{M}+\mathrm{H}]^{+} \mathrm{m} / \mathrm{e}: 375$ $(100 \%)$.

MKC3426 (2-hydroxy-3-methoxy-naphthalene-1-carbaldehyde). Commercially sourced from Ambinter (Cat. No. Amb18653768) or Aurora Fine Chemicals LLC (Cat. No. A07.180.446).

MKC3437 (2-hydroxy-1-naphthylaldehyde). Commercially sourced from Sigma-Aldrich (Cat. No. H45353-25G).

MKC3820 (2-hydroxy-1-acetonaphthylaldehyde). Commercially sourced from Sigma-Aldrich (Cat. No. 303054-25G).

MKC3964 (1-naphthylaldehyde). Commercially sourced from Sigma-Aldrich (Cat. No. N109-2G-A).

Modelling of the IRE1 $\alpha$-hydroxy-aryl-aldehyde-RNA substrate complex. The tRNA splicing endonuclease in complex with RNA substrate (PDB $2 \mathrm{GJW})^{47}$ was used as a template to model RNA substrate concurrently bound to murine IRE1 $\alpha$ and MKC9989 (Supplementary Fig. 3e) as performed previously for yeast IRE1 (ref. 11). In brief, the catalytic tetrad of the tRNA endonuclease (Tyr246, Ser258, His257 and Lys287) was superimposed manually onto the respective invariant catalytic tetrad (Tyr892, Asn906, His910 and Arg905) of mouse IRE1 $\alpha$. The two nucleotides flanking the scissile bond of the substrate RNA corresponding to chain E positions deoxy-uridine 14 and adenosine 15 were then excised and mutated to the IRE1 $\alpha$ substrate consensus guanosine followed by cytosine. The full structure of IRE1 $\alpha$, dinucleotide and MKC9989 was then energy minimized using Refmac ${ }^{59,60}$.

\section{References}

1. Cao, S. S. \& Kaufman, R. J. Targeting endoplasmic reticulum stress in metabolic disease. Expert Opin. Ther. Targets 17, 437-448 (2013).

2. Hetz, C., Chevet, E. \& Harding, H. P. Targeting the unfolded protein response in disease. Nat. Rev. Drug Discov. 12, 703-719 (2013).

3. Walter, P. \& Ron, D. The unfolded protein response: from stress pathway to homeostatic regulation. Science 334, 1081-1086 (2011).

4. Hetz, C., Martinon, F., Rodriguez, D. \& Glimcher, L. H. The unfolded protein response: integrating stress signals through the stress sensor IRE1alpha. Physiol. Rev. 91, 1219-1243 (2011).

5. Chen, X. et al. XBP1 promotes triple-negative breast cancer by controlling the HIFlalpha pathway. Nature 508, 103-107 (2014). 
6. Harding, H. P., Zhang, Y. \& Ron, D. Protein translation and folding are coupled by an endoplasmic-reticulum-resident kinase. Nature 397, 271-274 (1999).

7. Harding, H. P. et al. An integrated stress response regulates amino acid metabolism and resistance to oxidative stress. Mol. Cell 11, 619-633 (2003).

8. Haze, K., Yoshida, H., Yanagi, H., Yura, T. \& Mori, K. Mammalian transcription factor ATF6 is synthesized as a transmembrane protein and activated by proteolysis in response to endoplasmic reticulum stress. Mol. Biol. Cell 10, 3787-3799 (1999).

9. Yoshida, H. et al. ATF6 activated by proteolysis binds in the presence of NF-Y (CBF) directly to the cis-acting element responsible for the mammalian unfolded protein response. Mol. Cell. Biol. 20, 6755-6767 (2000).

10. Sidrauski, C. \& Walter, P. The transmembrane kinase Irelp is a site-specific endonuclease that initiates mRNA splicing in the unfolded protein response. Cell 90, 1031-1039 (1997).

11. Lee, K. P. et al. Structure of the dual enzyme Irel reveals the basis for catalysis and regulation in nonconventional RNA splicing. Cell 132, 89-100 (2008).

12. Wang, X. Z. et al. Cloning of mammalian Irel reveals diversity in the ER stress responses. EMBO J. 17, 5708-5717 (1998).

13. Tirasophon, W., Welihinda, A. A. \& Kaufman, R. J. A stress response pathway from the endoplasmic reticulum to the nucleus requires a novel bifunctional protein kinase/endoribonuclease (Irelp) in mammalian cells. Genes Dev. 12, 1812-1824 (1998).

14. Cox, J. S. \& Walter, P. A novel mechanism for regulating activity of a transcription factor that controls the unfolded protein response. Cell 87, 391-404 (1996)

15. Cox, J. S., Shamu, C. E. \& Walter, P. Transcriptional induction of genes encoding endoplasmic reticulum resident proteins requires a transmembrane protein kinase. Cell 73, 1197-1206 (1993).

16. Dong, B., Niwa, M., Walter, P. \& Silverman, R. H. Basis for regulated RNA cleavage by functional analysis of RNase L and Ire1p. RNA 7, 361-373 (2001).

17. Silverman, R. H. Viral encounters with $2^{\prime}, 5^{\prime}$-oligoadenylate synthetase and RNase L during the interferon antiviral response. J. Virol. 81, 12720-12729 (2007).

18. Shamu, C. E. \& Walter, P. Oligomerization and phosphorylation of the Irelp kinase during intracellular signaling from the endoplasmic reticulum to the nucleus. EMBO J. 15, 3028-3039 (1996).

19. Welihinda, A. A. \& Kaufman, R. J. The unfolded protein response pathway in Saccharomyces cerevisiae. Oligomerization and trans-phosphorylation of Irelp (Ernlp) are required for kinase activation. J. Biol. Chem. 271, 18181-18187 (1996).

20. Gonzalez, T. N., Sidrauski, C., Dorfler, S. \& Walter, P. Mechanism of nonspliceosomal mRNA splicing in the unfolded protein response pathway. EMBO J. 18, 3119-3132 (1999).

21. Calfon, M. et al. IRE1 couples endoplasmic reticulum load to secretory capacity by processing the XBP-1 mRNA. Nature 415, 92-96 (2002).

22. Shen, X. et al. Complementary signaling pathways regulate the unfolded protein response and are required for C. elegans development. Cell 107, 893-903 (2001).

23. Yoshida, H., Matsui, T., Yamamoto, A., Okada, T. \& Mori, K. XBP1 mRNA is induced by ATF6 and spliced by IRE1 in response to ER stress to produce a highly active transcription factor. Cell 107, 881-891 (2001).

24. Harding, H. P. et al. An intact unfolded protein response in Trptl knockout mice reveals phylogenic divergence in pathways for RNA ligation. RNA 14, 225-232 (2008).

25. Lee, A. H., Iwakoshi, N. N. \& Glimcher, L. H. XBP-1 regulates a subset of endoplasmic reticulum resident chaperone genes in the unfolded protein response. Mol. Cell. Biol. 23, 7448-7459 (2003).

26. Reimold, A. M. et al. Plasma cell differentiation requires the transcription factor XBP-1. Nature 412, 300-307 (2001).

27. Hollien, J. \& Weissman, J. S. Decay of endoplasmic reticulum-localized mRNAs during the unfolded protein response. Science 313, 104-107 (2006).

28. Hollien, J. et al. Regulated Ire1-dependent decay of messenger RNAs in mammalian cells. J. Cell Biol. 186, 323-331 (2009).

29. So, J. S. et al. Silencing of lipid metabolism genes through IRE1alphamediated mRNA decay lowers plasma lipids in mice. Cell Metab. 16, 487-499 (2012).

30. Martinon, F., Chen, X., Lee, A. H. \& Glimcher, L. H. TLR activation of the transcription factor XBP1 regulates innate immune responses in macrophages. Nat. Immunol. 11, 411-418 (2010).

31. Mao, T. et al. PKA phosphorylation couples hepatic inositol-requiring enzyme lalpha to glucagon signaling in glucose metabolism. Proc. Natl Acad. Sci. USA 108, 15852-15857 (2011).

32. Cho, J. A. et al. The unfolded protein response element IRElalpha senses bacterial proteins invading the ER to activate RIG-I and innate immune signaling. Cell Host Microbe 13, 558-569 (2013).

33. Lin, J. H. et al. IRE1 signaling affects cell fate during the unfolded protein response. Science 318, 944-949 (2007).
34. Rutkowski, D. T. et al. Adaptation to ER stress is mediated by differential stabilities of pro-survival and pro-apoptotic mRNAs and proteins. PLoS Biol. 4, e374 (2006).

35. Chawla, A., Chakrabarti, S., Ghosh, G. \& Niwa, M. Attenuation of yeast UPR is essential for survival and is mediated by IRE1 kinase. J. Cell Biol. 193, 41-50 (2011).

36. Rubio, C. et al. Homeostatic adaptation to endoplasmic reticulum stress depends on Ire1 kinase activity. J. Cell Biol. 193, 171-184 (2011).

37. Korennykh, A. V. et al. The unfolded protein response signals through highorder assembly of Ire1. Nature 457, 687-693 (2009).

38. Papa, F. R., Zhang, C., Shokat, K. \& Walter, P. Bypassing a kinase activity with an ATP-competitive drug. Science 302, 1533-1537 (2003).

39. Wang, L. et al. Divergent allosteric control of the IRE1alpha endoribonuclease using kinase inhibitors. Nat. Chem. Biol. 8, 982-989 (2012).

40. Wiseman, R. L. et al. Flavonol activation defines an unanticipated ligand-binding site in the kinase-RNase domain of IRE1. Mol. Cell 38, 291-304 (2010).

41. Volkmann, K. et al. Potent and selective inhibitors of the inositolrequiring enzyme 1 endoribonuclease. J. Biol. Chem. 286, 12743-12755 (2011).

42. Mimura, N. et al. Blockade of XBP1 splicing by inhibition of IRE1alpha is a promising therapeutic option in multiple myeloma. Blood 119, 5772-5781 (2012).

43. Cross, B. C. et al. The molecular basis for selective inhibition of unconventional mRNA splicing by an IRE1-binding small molecule. Proc. Natl Acad. Sci. USA 109, E869-E878 (2012).

44. Mahoney, D. J. et al. Virus-tumor interactome screen reveals ER stress response can reprogram resistant cancers for oncolytic virus-triggered caspase- 2 cell death. Cancer Cell 20, 443-456 (2011).

45. Oikawa, D., Tokuda, M. \& Iwawaki, T. Site-specific cleavage of CD59 mRNA by endoplasmic reticulum-localized ribonuclease, IRE1. Biochem. Biophys. Res. Commun. 360, 122-127 (2007)

46. Ali, M. M. et al. Structure of the Ire1 autophosphorylation complex and implications for the unfolded protein response. EMBO J. 30, 894-905 (2011).

47. Xue, S., Calvin, K. \& Li, H. RNA recognition and cleavage by a splicing endonuclease. Science 312, 906-910 (2006).

48. Kornev, A. P., Haste, N. M., Taylor, S. S. \& Eyck, L. F. Surface comparison of active and inactive protein kinases identifies a conserved activation mechanism. Proc. Natl Acad. Sci. USA 103, 17783-17788 (2006).

49. Vladykovskaya, E. et al. Lipid peroxidation product 4-hydroxy-trans-2-nonenal causes endothelial activation by inducing endoplasmic reticulum stress. J. Biol. Chem. 287, 11398-11409 (2012).

50. Lowrey, C. H., Lyness, S. J. \& Soeldner, J. S. The effect of hemoglobin ligands on the kinetics of human hemoglobin Alc formation. J. Biol. Chem. 260, 11611-11618 (1985).

51. Rolan, P. E., Mercer, A. J., Wootton, R. \& Posner, J. Pharmacokinetics and pharmacodynamics of tucaresol, an antisickling agent, in healthy volunteers. Br. J. Clin. Pharmacol. 39, 375-380 (1995).

52. Qiu, Q. et al. Toll-like receptor-mediated IRE1alpha activation as a therapeutic target for inflammatory arthritis. EMBO J. 32, 2477-2490 (2013).

53. Kabsch, W. XDS. Acta Crystallogr. D Biol. Crystallogr. 66, 125-132 (2010).

54. Strong, M. et al. Toward the structural genomics of complexes: crystal structure of a PE/PPE protein complex from Mycobacterium tuberculosis. Proc. Natl Acad. Sci. USA 103, 8060-8065 (2006).

55. McCoy, A. J. et al. Phaser crystallographic software. J. Appl. Crystallogr. 40, 658-674 (2007).

56. Adams, P. D. et al. PHENIX: a comprehensive Python-based system for macromolecular structure solution. Acta Crystallogr. D Biol. Crystallogr. 66, 213-221 (2010).

57. Emsley, P., Lohkamp, B., Scott, W. G. \& Cowtan, K. Features and development of Coot. Acta Crystallogr. D Biol. Crystallogr. 66, 486-501 (2010).

58. Moriarty, N. W., Grosse-Kunstleve, R. W. \& Adams, P. D. electronic Ligand Builder and Optimization Workbench (eLBOW): a tool for ligand coordinate and restraint generation. Acta Crystallogr. D Biol. Crystallogr. 65, 1074-1080 (2009).

59. Murshudov, G. N. et al. REFMAC5 for the refinement of macromolecular crystal structures. Acta Crystallogr. D Biol. Crystallogr. 67, 355-367 (2011).

60. Winn, M. D. et al. Overview of the CCP4 suite and current developments. Acta Crystallogr. D Biol. Crystallogr. 67, 235-242 (2011).

\section{Acknowledgements}

This work was supported by a grant to F.S. from the Canadian Institutes of Health Research (MOP 84370) and a Multiple Myeloma Research Foundation Biotech Investment Award to MannKind Corporation. We would like to thank Gary Flynn, David Lonergan, Peter Pallai, Warren Wade, Zoltan Zubovics, Yun Yang and Zhipeng Wu for chemistry support. We thank the Advanced Photon Source on the 
Northeastern Collaborative Access Team beam lines, supported by a grant from the National Institute of General Medical Sciences (P41 GM103403) from the National Institutes of Health and by the U.S. DOE under contract No. DE-AC02 06CH11357. M.S was supported through a Canadian Cancer Society Postdoctoral Fellowship.

\section{Author contributions}

M.S. and M.T. performed the co-structure determinations. N.M.D., M.T., L.L. and M.C. performed in vitro enzymatic assays and direct inhibitor-binding measurements. D.C., N.M.D., M.T., N.T. and K.L. performed biophysical analyses and/or generated reagents. I.K. collected synchrotron diffraction data. D.U., R.A.-a., G.P., M.P. and B.W. chemically synthesized OICR573 and OICR464. V.T., C.S., A.T., J.L.L., D.V. and Q.Z. performed cell analyses, enzyme assays and directed the synthesis of MKC9989, MKC3946, MKC3987 and MKC4027. D.D. supervised M.C., F.S. and J.B.P. designed the experiments and interpreted the results. F.S. and J.B.P. wrote the manuscript with contributions from all other authors.

\section{Additional information}

Accession codes: Final coordinates and structure factors for the IRE1 $\alpha$-MKC9989, IRE1 $\alpha$-OICR573 and IRE1 $\alpha$-OICR464 co-structures have been deposited to the PDB with the respective accession codes: 4PL3, 4PL4 and 4PL5.

Supplementary Information accompanies this paper at http://www.nature.com/ naturecommunications

Competing financial interests: V.T., C.S., A.T., J.L.L., D.V., Q.Z. and J.P. are past or present employees of MannKind Corporation and F.S. was a paid consultant of MannKind Corporation. The remaining authors declare no competing financial interests.

Reprints and permission information is available online at http://npg.nature.com/ reprintsandpermissions/

How to cite this article: Sanches, M. et al. Structure and mechanism of action of the hydroxy-aryl-aldehyde class of IRE1 endoribonuclease inhibitors. Nat. Commun. 5:4202 doi: $10.1038 /$ ncomms5202 (2014). 